ISSN 2076-0752

www.mdpi.com/journal/arts

Article

\title{
Rock Art of Saudi Arabia
}

\section{Majeed Khan}

Consultant archaeologist, Saudi Commission for Tourism and Antiquities, P.O. Box 3734, Riyadh 11481, Kingdom of Saudi Arabia; E-Mail: majeedkhan1942@yahoo.com;

Tel.: +9661-4029500.

Received: 5 September 2013; in revised form: 28 October 2013 / Accepted: 27 November 2013 / Published: 13 December 2013

\begin{abstract}
It is not only oil in which Saudi Arabia is rich, but it is also among the four richest rock art regions of the world. Hundreds and thousands of petroglyphs, painted rock art, and ancient Arabian inscriptions sites are located all over the country, representing various cultural phases, from the Neolithic until the recent past. One can see the naturalistic, schematic, abstract, mythical, and mystical images representing ancient ideology, thoughts about the metaphysical world, religious entity, economy, environment, human activities, and variety of animal types, according to particular climatic and environmental conditions. The rock art of Saudi Arabia is the mirror of its rich cultural heritage of so-called Bedouin or desert dwellers that surprises the world with its 4000 archaeological and more than 1500 rock art sites.
\end{abstract}

Keywords: Neolithic; petroglyph; painted site; heritage; ideology; environment; naturalistic; schematic; mirror of human behavior 
Arts 2013, 2

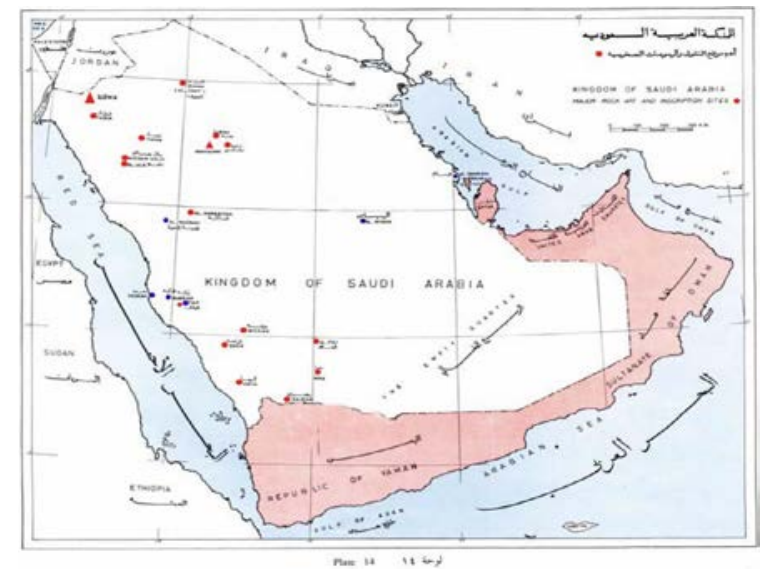

\section{Introduction}

Saudi Arabia is rich in its cultural heritage. There are over 4000 archaeological and 1500 rock art sites so far located in the Kingdom. The chronology of Saudi Arabian archaeology indicates a continuity of human presence in the Arabian Peninsula, from Acheulian to the present day [1]. However, the rock art of Saudi Arabia represents an era from early Neolithic to early Islamic period ca. 1350 years BP [2,3,4].

Thousands of rock art sites are located all over the country. The art can be attributed to the prehistoric people and to the tribal nomads wandering in the deserts of Arabia. Some of the Arabian dances and cultural contents show a continuity of ancient traditional cultural activities from times unknown [5,3]

Saudi Arabian rock art in general and that of the Arabian Peninsula in particular is enriched with a variety of human and animal figures in addition to geometric and non-representational motifs. On the basis of difference in patina, overlapping, superimpositions, and relation with the cultural objects located on or near the petroglyph sites, a tentative and relative chronology of Saudi Arabian rock art has been prepared by this researcher [3,4]. However, the precise chronological dates are difficult to obtain for the petroglyphs and may be debated, but the relative sequence of phases is clear and widely accepted, in most of the cases.

In several presumed compositions that could be attributed to the Neolithic period, human figures are associated with animals, particularly bovid and canine, in situations as if the animal was following the person. It appears that the two animals were domesticated and were part of the daily life, as well as social and cultural activities. While, in almost all cases human faces are ambiguous, necks are long, and heads and faces are obscure (Figure 1), perhaps representing images of metaphysical world with human-like bodies and abstract faces. 
Arts 2013, 2

Figure 1. Human form holding what looks like a boomerang from Jubbah, followed by what looks like a bovid, located at Jubbah, Northern Arabia.

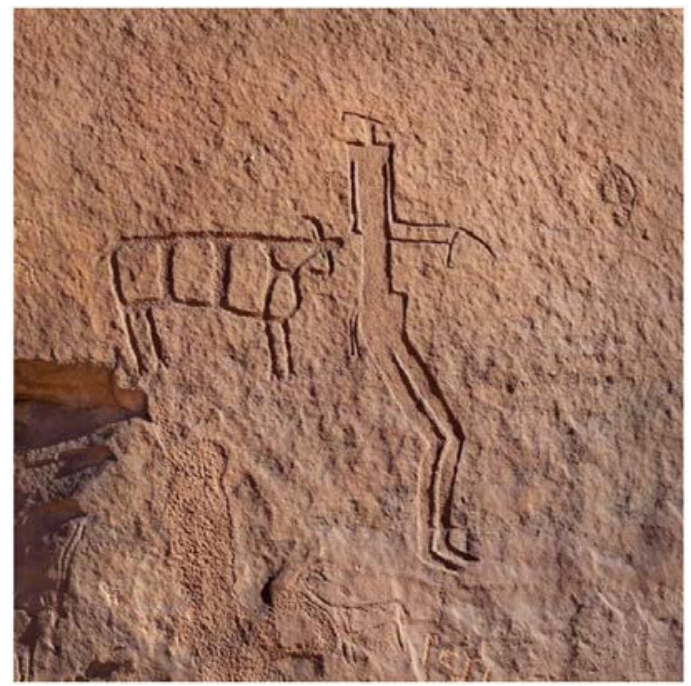

Saudi Arabia is enriched with a variety of anthropomorphs and zoomorphs in addition to geometric and apparently non-representational motifs. The Neolithic rock art of Saudi Arabia reflects a quite significant cognitive system in which all the social groups, tribes, or clans appear to have shared a common cosmology in which a single animal species, the cattle, was particularly, and overwhelmingly depicted [6] (Figure 2). When cattle were domesticated on large scale they were branded with certain geometric motifs.

Figure 2. Bovid representing cool and humid climate, while camel superimposed on it is the animal of hot and dry conditions. The difference in patina clearly shows a difference of several thousand years between the two images.

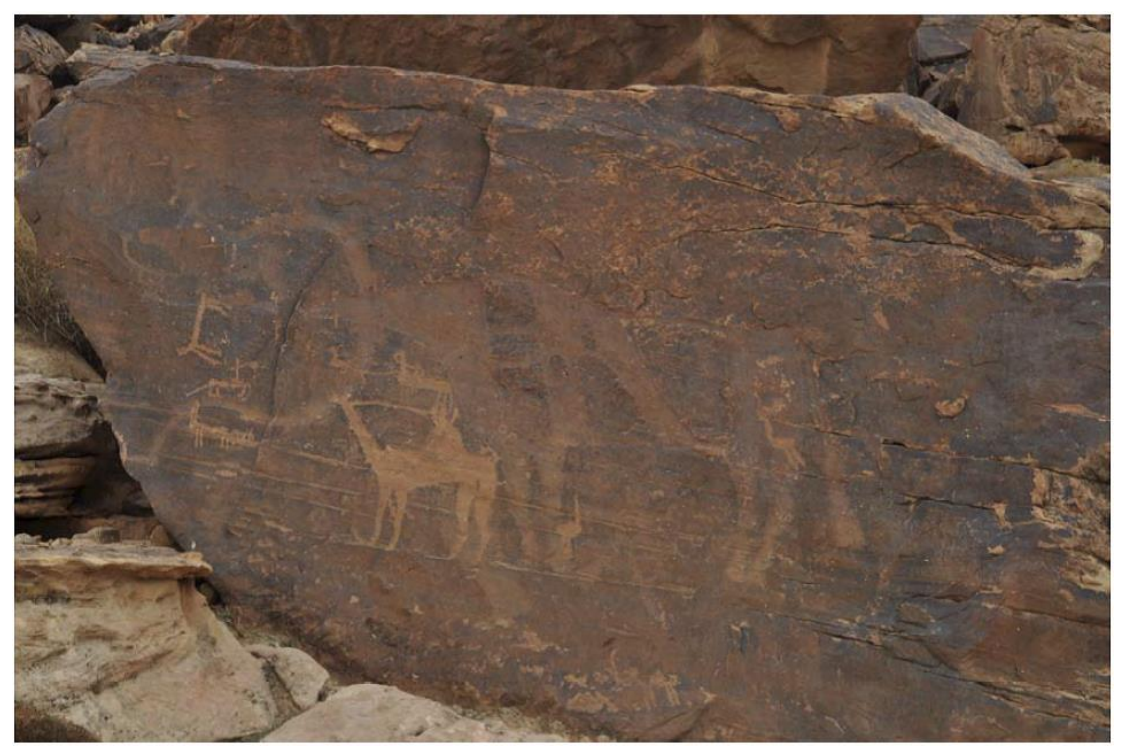


When the climate of Saudi Arabia changed rapidly from cool and humid in the Neolithic, to extremely hot and arid in the Bronze Age ca. 4500 years BP [7,8] cattle gradually disappeared and were replaced by camels, which were domesticated on a large scale. Consequently, the cattle brands became camel brands. It is not clear when the camel was first domesticated in Arabia, but it was represented on a large scale as a domesticated animal in the Bronze Age.

Figure 3 appears to represent a social or religious event in which people are apparently dancing. In almost all cases faces of these Neolithic anthropomorphs are ambiguous and absent (see also Figure 4).

Figure 3. Apparently women, with protruding buttocks, in dancing attitude, Shuwaymis, northern region. Clear sexual traits are extremely rarely to be indicated on the human figures in Saudi Arabia. It is assumed by this author that the women in the rock art compositions of Arabia are usually represented by wide and protruding buttocks, and men with slender flat bodies [9].

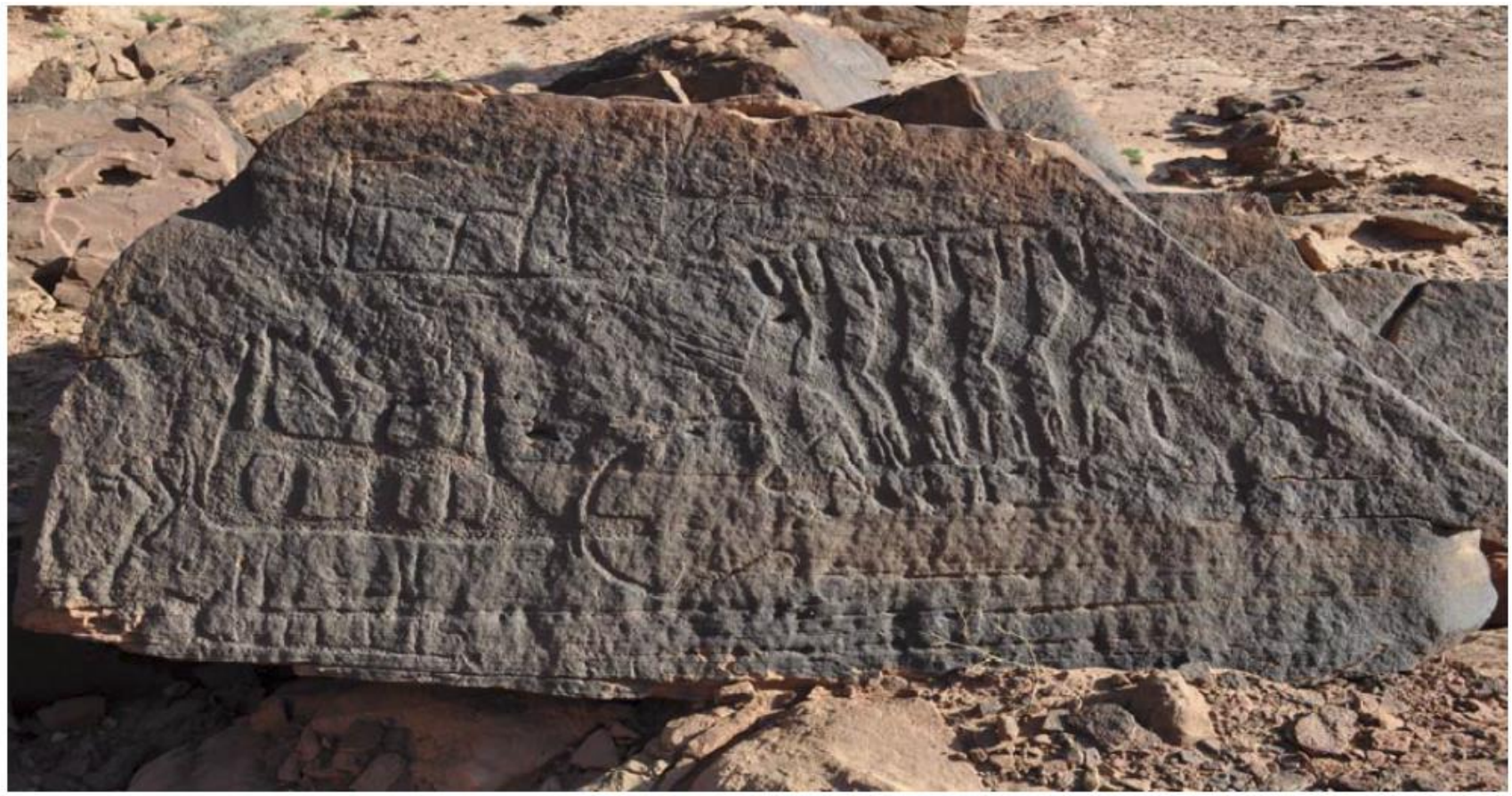


Figure 4. Tracing of a panel. Anthropomorphous representations, probably in dancing attitude, Jubbah,_Northern Arabia.

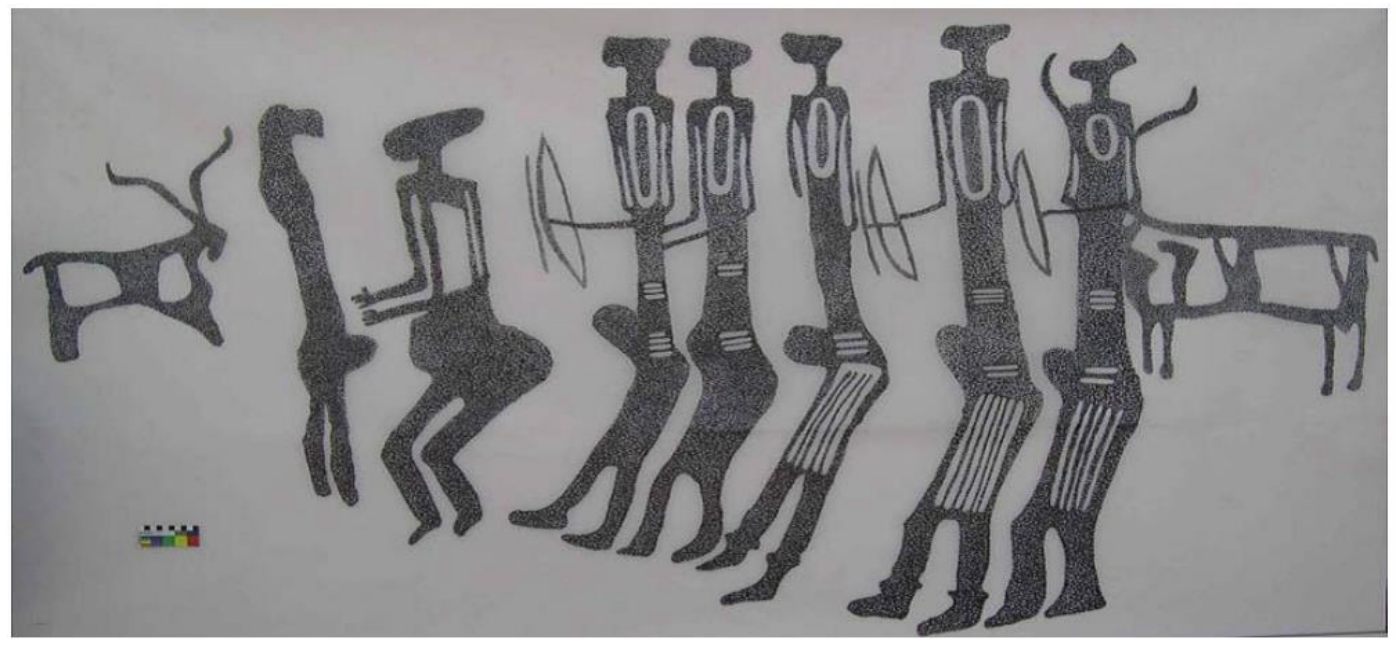

It is suggested that, in most cases, animals are shown hunted by bow and arrows, with arrows depicted near the hunted or wounded animal, but it is not clear whether the "scenes" represent true wounded animals or just symbolic hunting scenes. It is not known whether the hunting scenes were created for sympathetic magic, record of an event, or the rituals were performed on the site for the successes in the hunt or to increase the number of animals. Such suggestions could only be hypothetical or assumptions of our modern minds (Figures 5 and 6).

Figure 5. A large composition of human and animal figures at Shuwaymis, northern region.

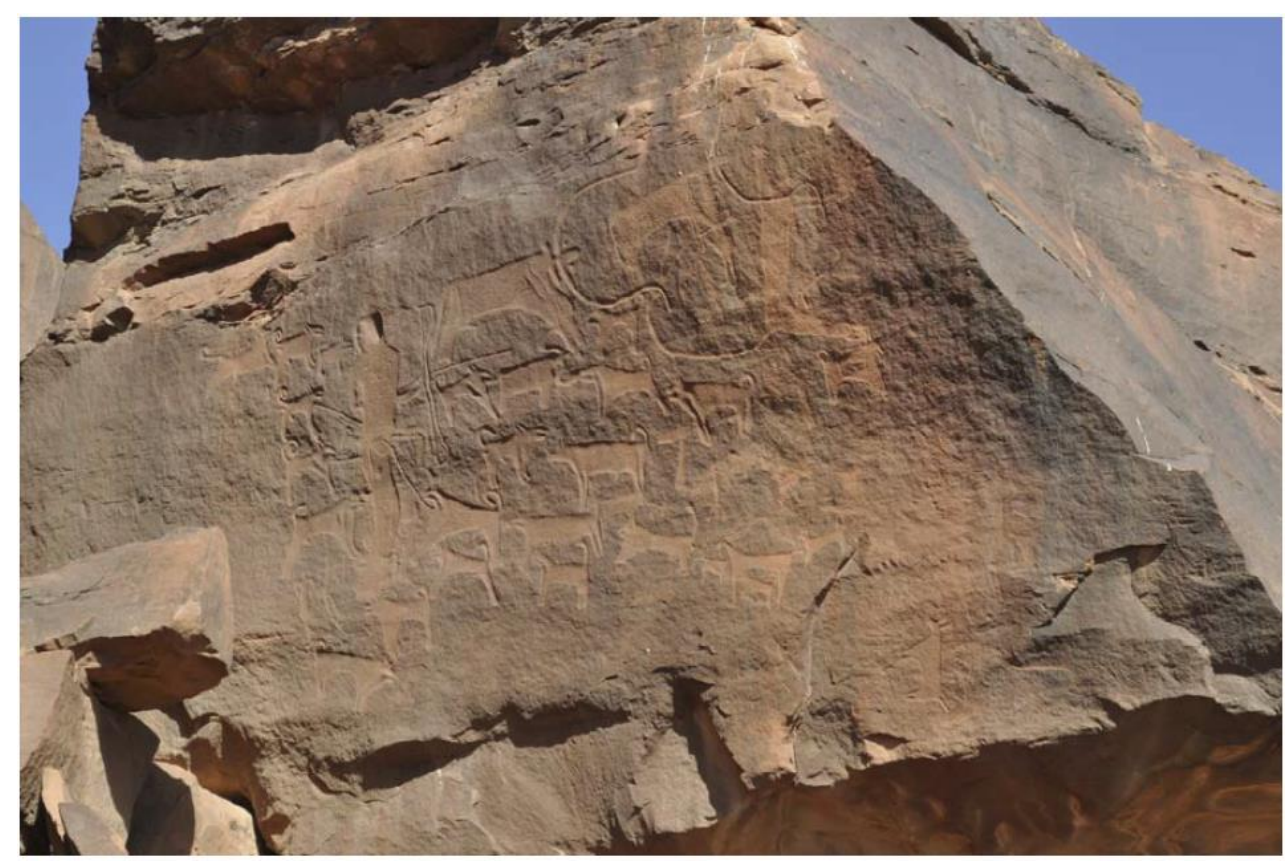


Figure 6. Neolithic society depended on hunting and food gathering. In this image an animal seems to be carried by the people. Jubbah, northern region.

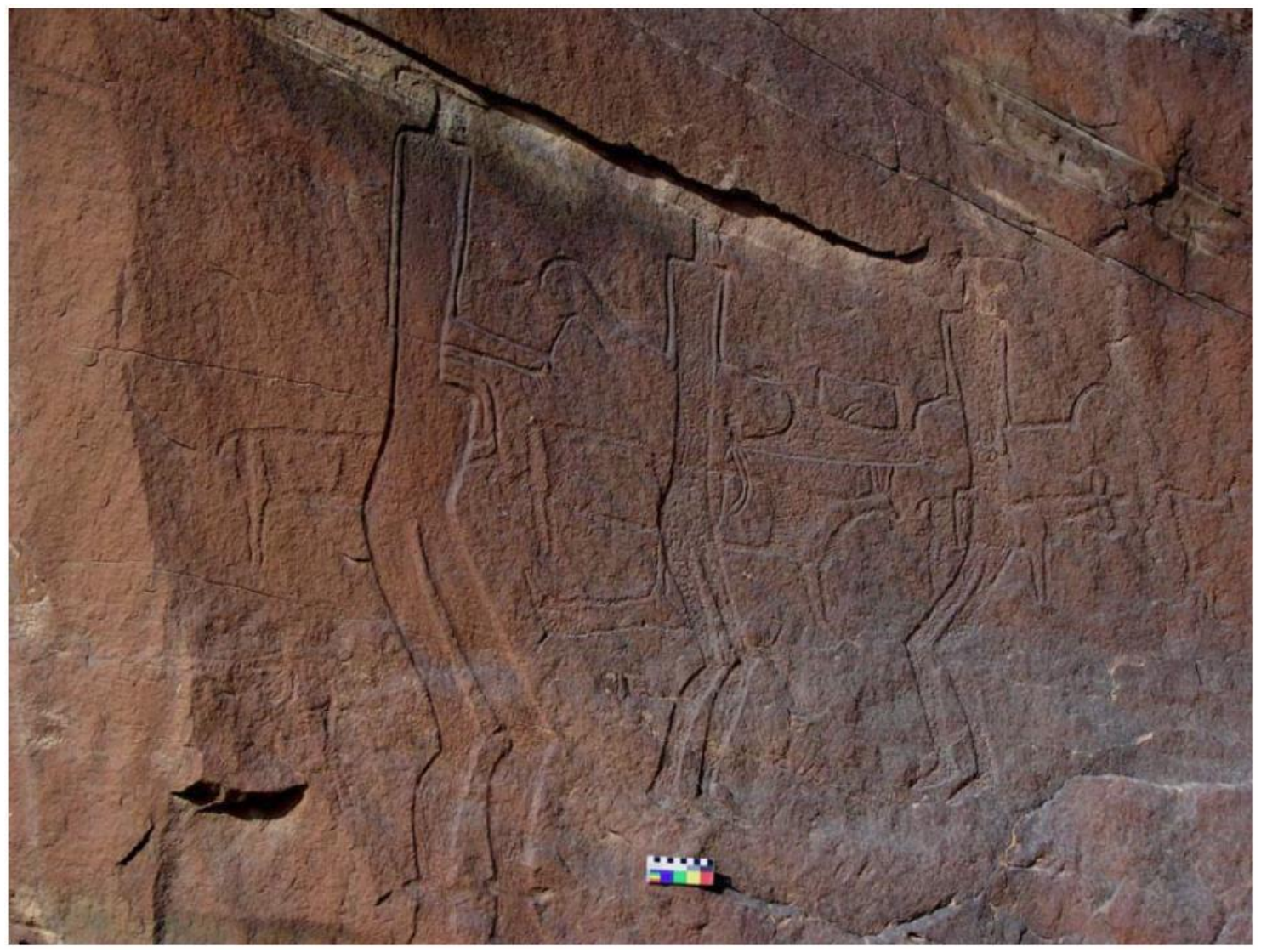

\section{Chronology}

The chronology of Saudi Arabian rock art remains largely tentative and relative. Almost all the sites are open air, roughly and deeply pecked or chiseled petroglyphs, and few motifs have been scientifically dated so far $[10,11]$. This tentative relative chronology suggests that the figures of the earliest phase 1 , tentatively attributed to the Neolithic, are distinctive in having large-sized human and animal figures depicted in low or bas-relief with detailed realistic physical features, except the faces, which are usually obscure and ambiguous (Figure 7). The art of the later Neolithic period, associated with the coarse pottery of Saudi Arabia, represents the highly skilled and artistic images of human and animal representations (Figure 8), parallels of which do not exist anywhere in the Arabian Peninsula [2,3]. 
Figure 7. Strange, human-like figures in standing a profile form, located at Jubbah (left) and Shuwaymis (right), northern region. The ambiguous faces and long narrow necks are typical features of the Neolithic art in Arabia.
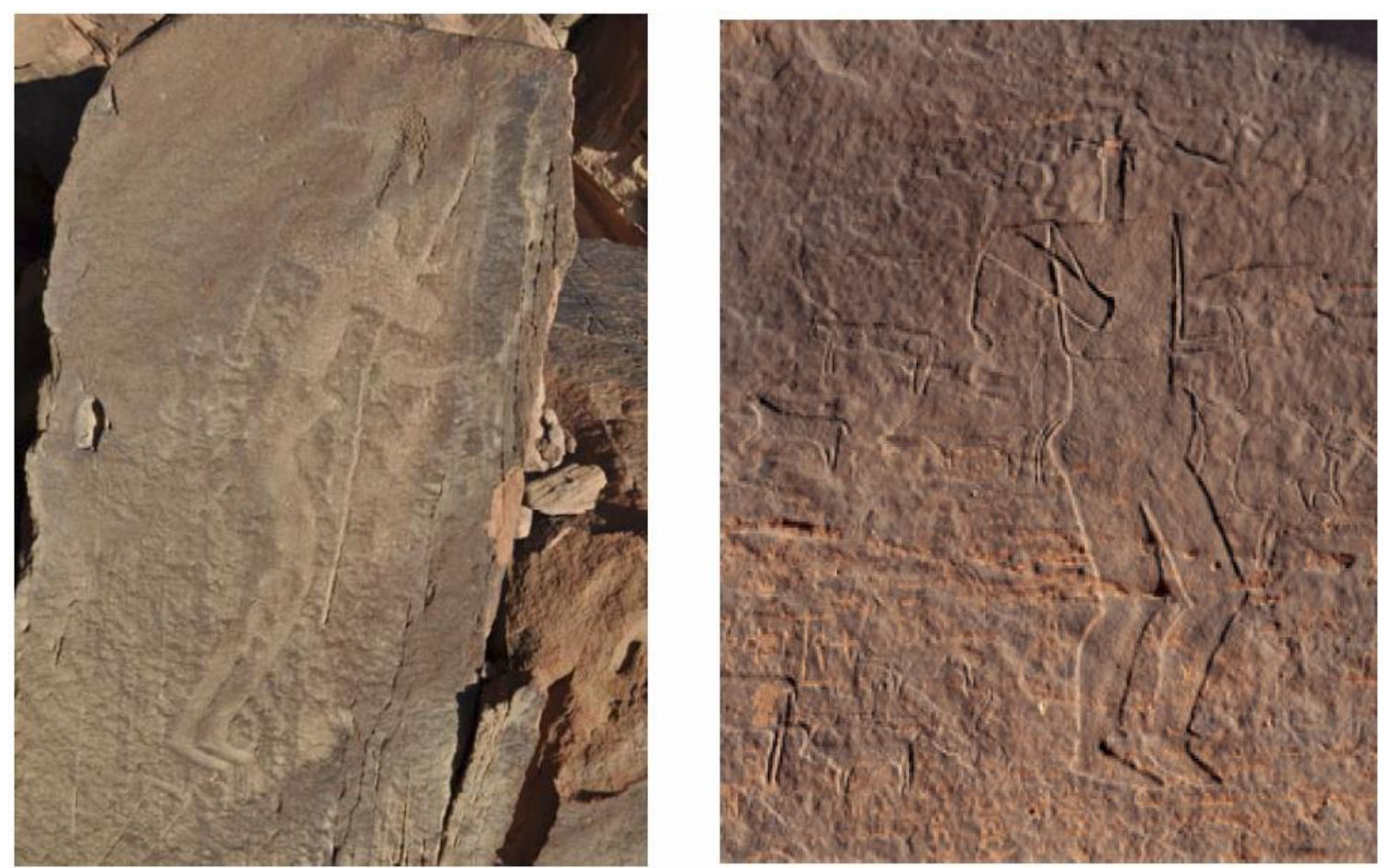

Figure 8. Assuming that this is a composition, it could be interpreted as attacking a wild donkey or other equid by bow and arrow and hunting with the help of dogs. Shuwaymis, northern region.

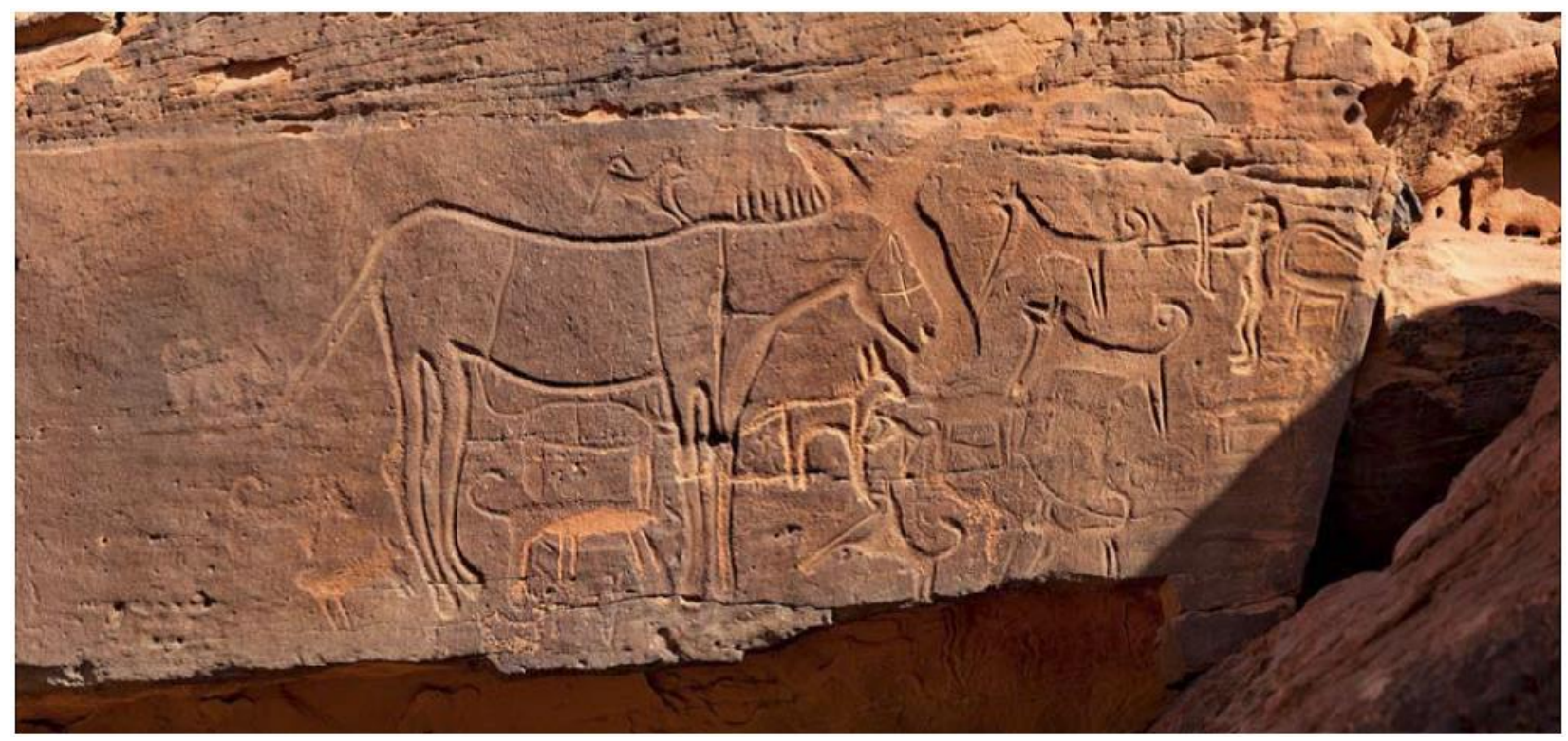


In the following period, or phase II (based on superimpositions), a change occurred in the art style and no more large-sized human and animal figures, with so-called realistic physical features, were produced. Instead, the figures became comparatively smaller and schematized. The typical funnel-shaped faces of bovids of phase 1 were replaced by triangular or conicalshaped faces, while the horns remained exaggeratedly large and highly stylized [9].

In the subsequent phase III, large compositions of human and animal figures, associated with a variety of animal species and non-representational and geometric motifs, suggest that the rock art gradually changed, both in its course and purpose. The figures became schematic, mostly outlined, and, for the first time, stick or linear, and simplified human and animal figures appeared in rock art compositions [12] This marked the beginning of a new trend in rock art in which foot and hand prints, meandering figures, along with a variety of animal species, such as presumed camels, ibex, deer, lions, dogs, wolves, and gazelles, became common elements of rock art compositions.

Phase IV is represented by a period preceding the introduction of writing or the literary period in Arabia. Highly schematic, abstract, stick-like linear human and animal figures, along with geometric and non-representational motifs, were depicted as signs and symbols replacing seminaturalistic and schematized art. With the change in Arabian climate and environmental conditions, from cool and humid in the Neolithic to the extremely hot and dry in the Bronze Age $[8,13,7,9]$, the camel became the main animal of rock assemblages (Figure 9). However, the tradition of depicting certain geometric and non-representational motifs on camel bodies as animal brand and tribal symbols (Wusum), continued until the present day [14,15].

Figure 9. Presumably wild camels are apparently being hunted by horse riders, Najran, Southern Arabia.

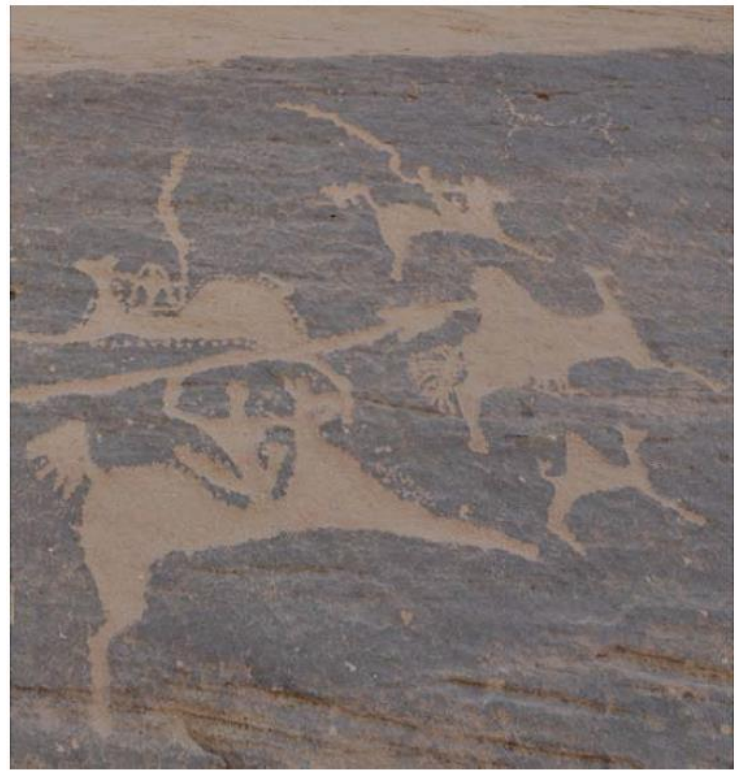




\section{Durability of Tribal Symbols}

Geometric and non-representational motifs suggest a deviation from the normal traditional artistic activities in which artists usually portrayed seen objects of nature, such as human and animal figures. The creation of signs and symbols for the purpose of showing tribal affinity, animal brands, or the like could have been the first step toward the origin of symbolic and coded communication systems. These could ultimately have led the artist toward further simplification of human and animal figures, the introduction of additional geometric and non-representational motifs, and finally developing a pictographic-cum-symbolic communication system. It is vital to note that how, in a non-literate society, certain signs became semantic, and a communication system was developed through certain coded characters, which were either in use in the prehistoric rock art or were later created according to need. Although rock art practice largely ceased in Arabia after the advent of Islam, about 1350 years ago (Islam prohibits drawing human figures, but camel figures and some non-human figures were depicted by the Bedouins until the recent past). The present Bedouins have absolutely no idea of rock art located in their territories but they still use Wusum as tribal symbols, animal brands, and territorial demarcation signs.

The gradual change in style, contents, context, and conceptuality, from prehistoric to Bedouin or tribal art could be clearly defined on the basis of animal representations, tribal symbols, and Bedouin writings that developed later in the Iron Age. Bedouin folk dances, branded camel figures, and the names of tribes and persons engraved besides rock art compositions testify to the fact that rock art played an important role in describing the social, cultural, and religious entities of Arabia from prehistoric to the early Islamic period. Hundreds and thousands of human, animal geometric, and non-representational figures, located on rocks and hills all over the country, suggest a well-developed system of pictographic communication and reveal everyday human activities of that time $[16,9,4]$.

With the establishment of large-scale communities, developments of tribes and clans, and the beginning of large-scale domestication of camels, appeared the use of animal brands, locally called Wusum. In Arabia, Wusum, or animal brands, were used for several purposes and were multifunctional, such as marking territorial boundaries and as symbols of tribes, signature on documents, grave marks, and as property brands, depicted on tents and camping sites [14,9] (Figures 10 and 11). 
Figure 10. A horse figure associated with a tribal symbol, indicating the name of the tribe or person.

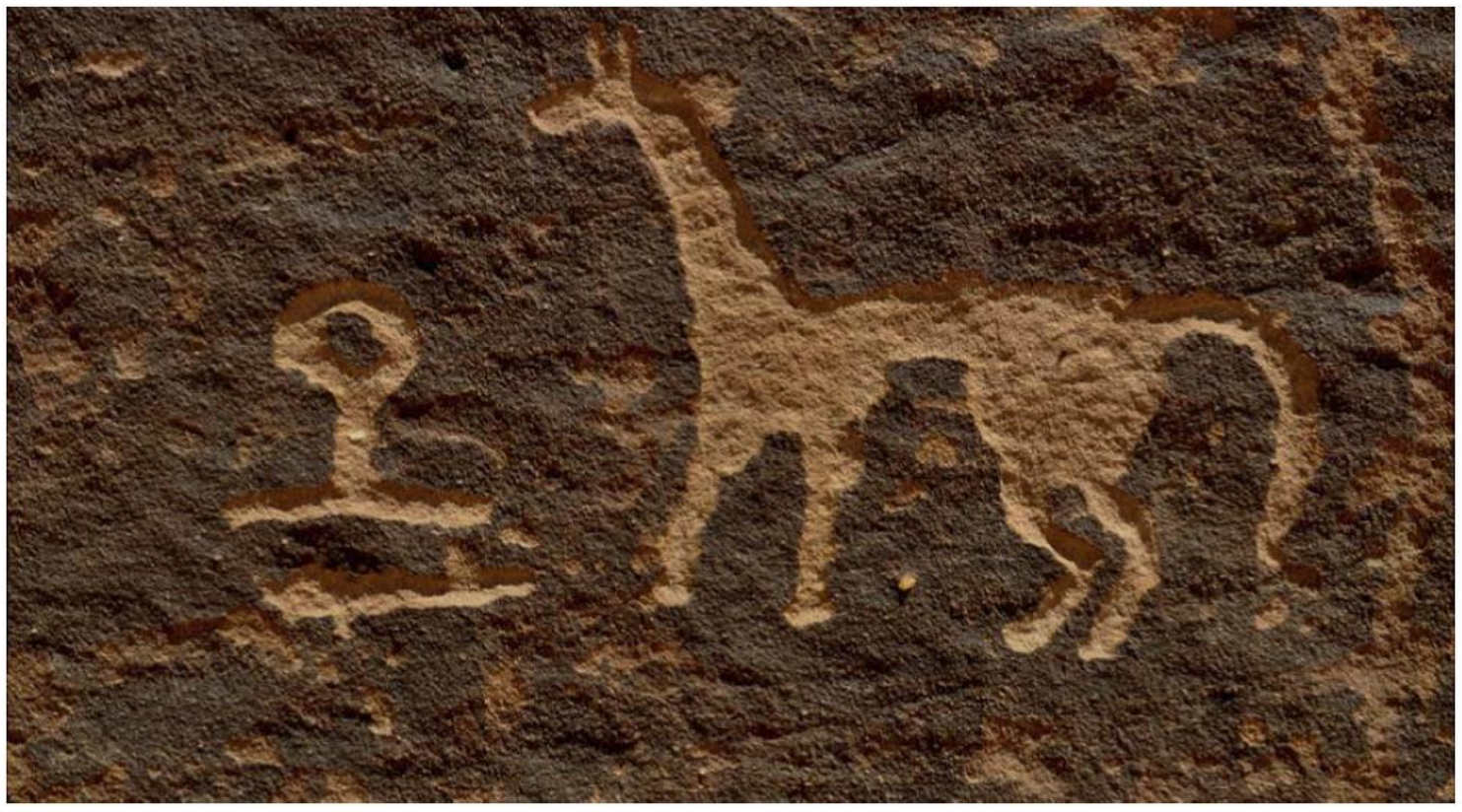

Figure 11. Camel and sheep with Wasum, or tribal symbols, marked on their bodies.

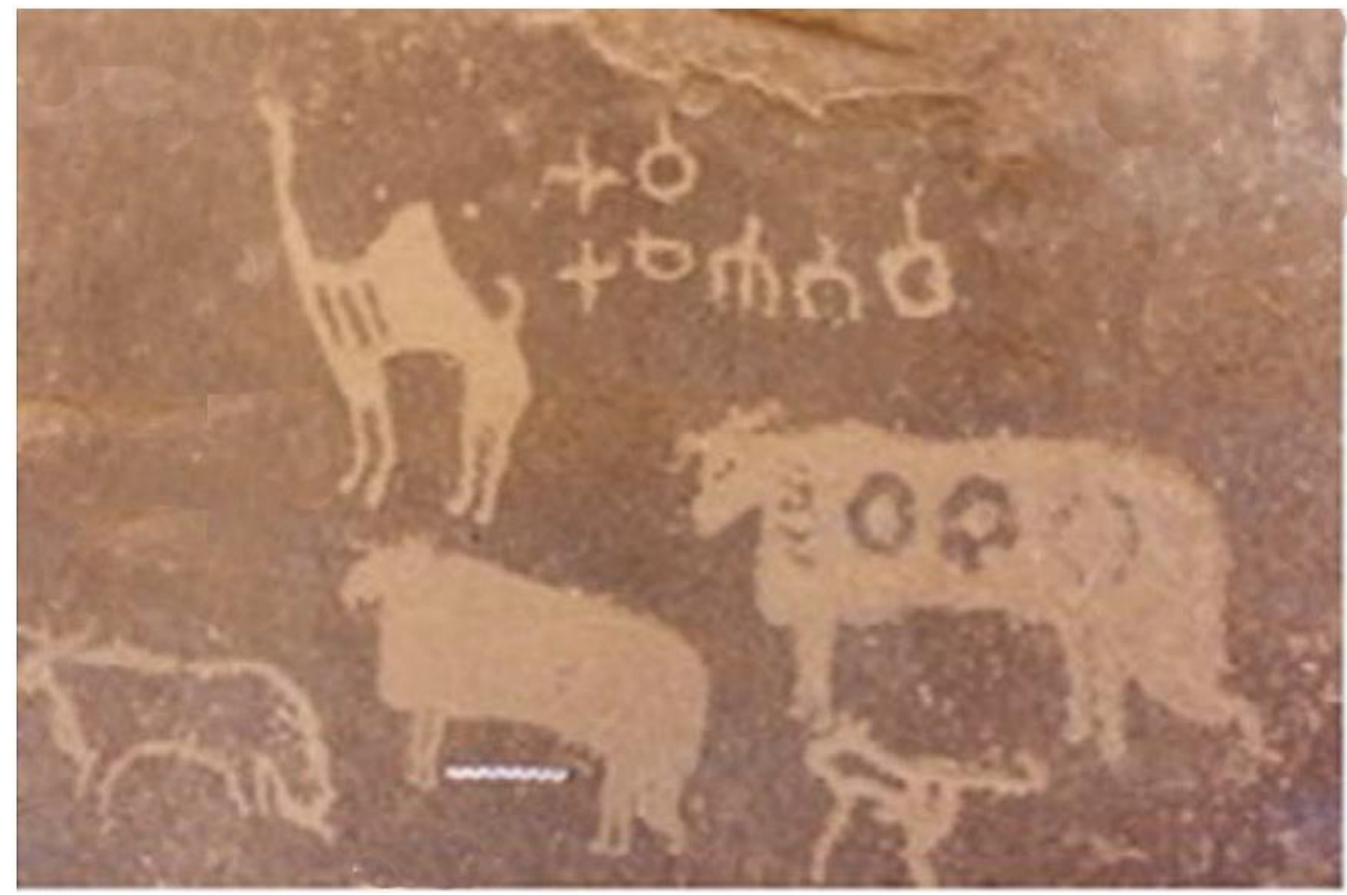

Although branding animals is a worldwide phenomenon and is still practiced in many countries of the world, in Arabia it is a deeply rooted ancient tradition. The pristine Arab tribes, still living in the desert, called "Bedouins", use certain geometric and non-representational 
motifs as "tribal symbols". These Arab tribes, being confined to their territories since antiquity, are still holding intact their social and cultural values.

\section{Anthropomorphs}

In ancient Arabia there was a tradition to carve and engrave the images of deities on rocks. Thus, un-walled open-air temples were created in the deserts, several of which still survive. The variety of gods on rocks, hills, and idols sculptured on the rocks represent a variety of human beliefs, thoughts, ideas, and the metaphysical world in which people believed $[17,18]$.

Idols were worshipped in pre-Islamic Arabia. For the Bedouins (the desert nomads) it was not possible to build temples in the desert, which could be buried in the shifting sands. They, however, created open-air temples and depicted images of their deities on rocks at high places (Figures 12 and 13). Such open-air worshipping sites could survive both the sand storms and shifting sand dunes.

Figure 12. In Wadi Damm, northwest of Tabuk, this composition of idoliform and bovid representations constitutes an open-air temple in the middle of the desert. Bulls were sacred animals, both in prehistoric Arabia and in Egypt [17,18]. The panel is located at about $5 \mathrm{~m}$ high on the smooth sandstone hill surface. High skill and advanced technology was used in creating this splendid and amazing work of art that still survived until now. The date of the rock art is unknown.

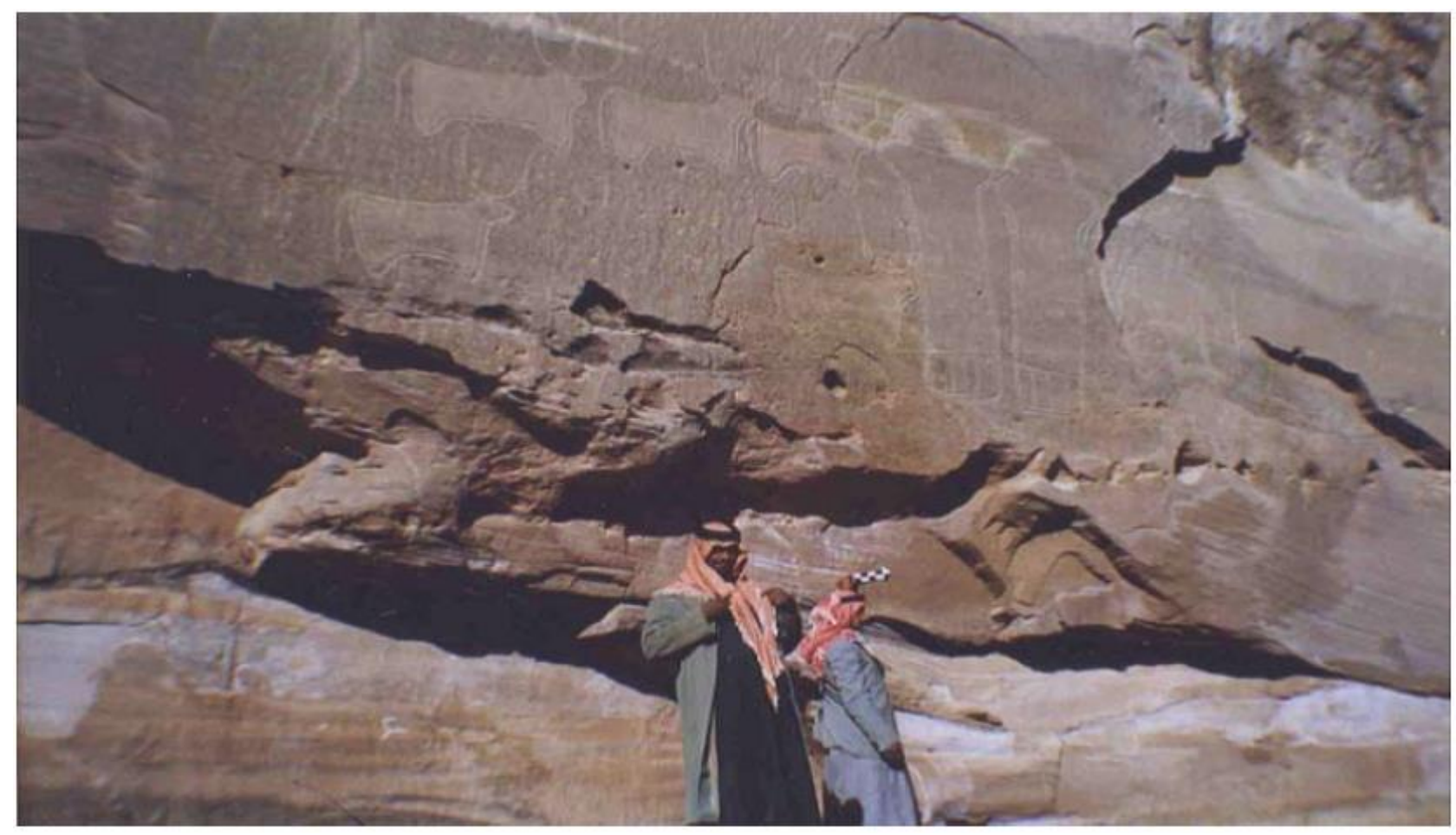


Figure 13. Some of the rock art sites are located in isolated desert places.

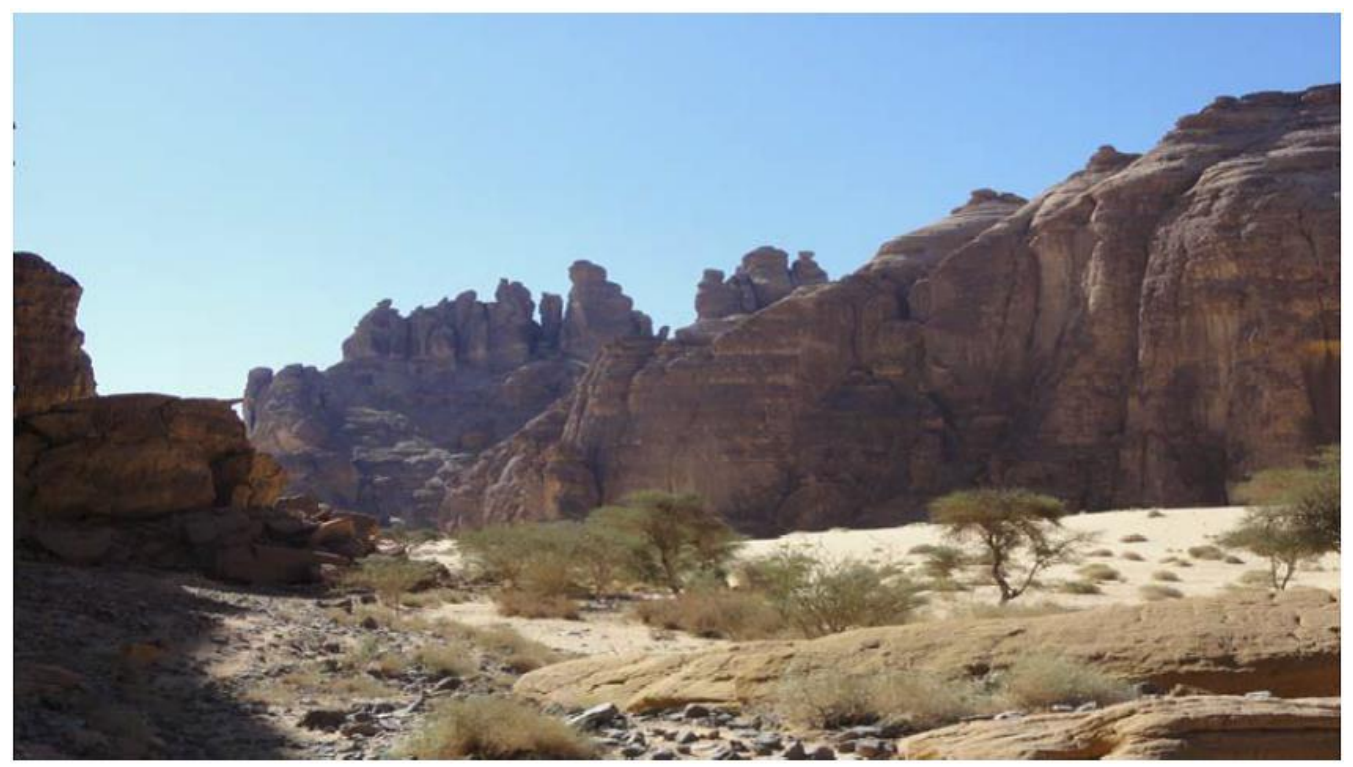

One such site is located in a depression of U-shaped valley between Jabal al Kaukab and Jabal al Qara, in the Najran area (Figure 14). It was, and still is, a rainwater reservoir. Rock shelters, availability of water, and some plants in the area made it a most attractive site for social and religious gatherings. Rituals might have been performed and, on each occasion, an icon of the goddess (Figures 15 and 16) was created on the same site. The site continued to be a gathering place for a long time as there are hundreds of ancient Arabian inscriptions carved all around the water reservoir on the hill surface.

Figure 14. Alia and several Thamudic inscriptions are carved on the hill around the rain water reservoir at the base of Jabal al-Kaukab, Najran.

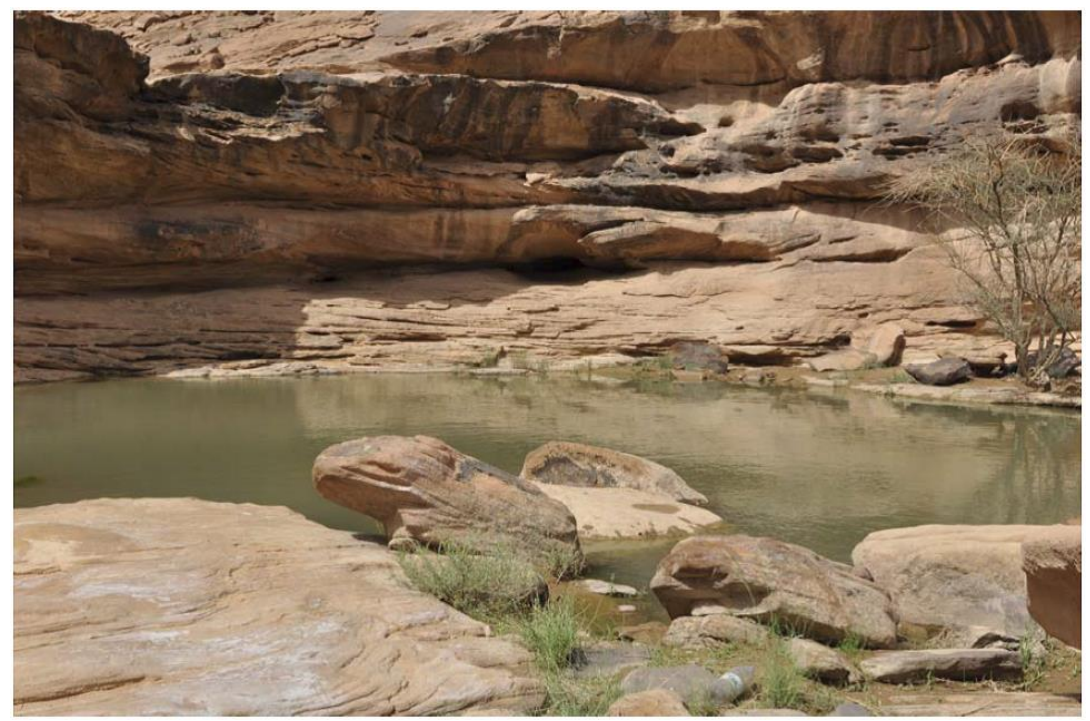


Figure 15. Female figures superimposed on earlier Bedouin inscriptions suggest their literate period age ca. 2500-2000 BP. Triangular torso, long neck, narrow waist, wide buttocks, and long hair are not less than the specifications of present day Miss World. We may assume that the artist may have deliberately kept the face obscure. The local Bedouin call it the image of a goddess “Alia”, a prehistoric queen and goddess ruling all over Southern Arabia. Although it is a legend, and apparently seems to be a story, this is the only figure in Arabian rock art with ethnological information. Images of Alia are overwhelmingly depicted on many sites in Najran area and further south in Northern Yemen.

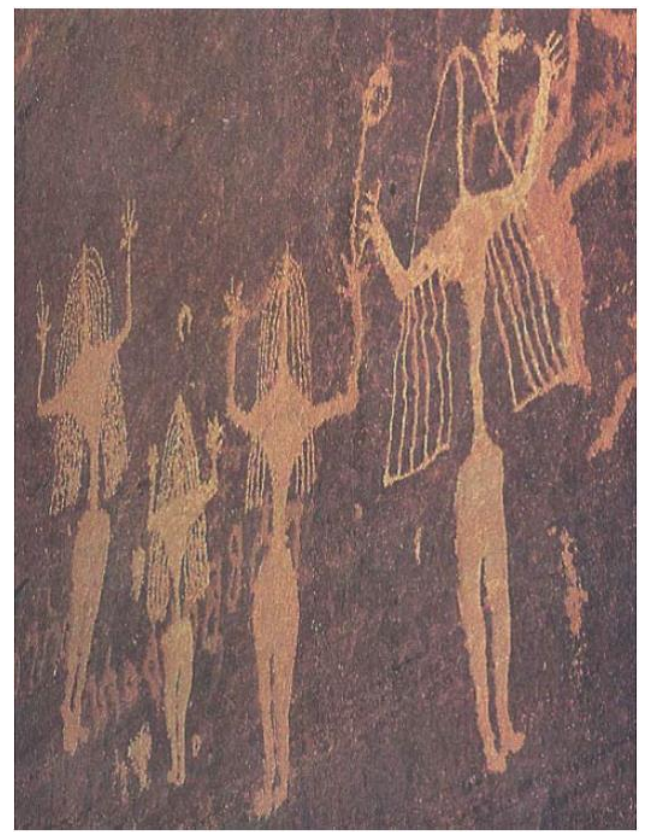

Figure 16. Several figures of “Alia” are located on a prominent higher and vertical surface of a hill.

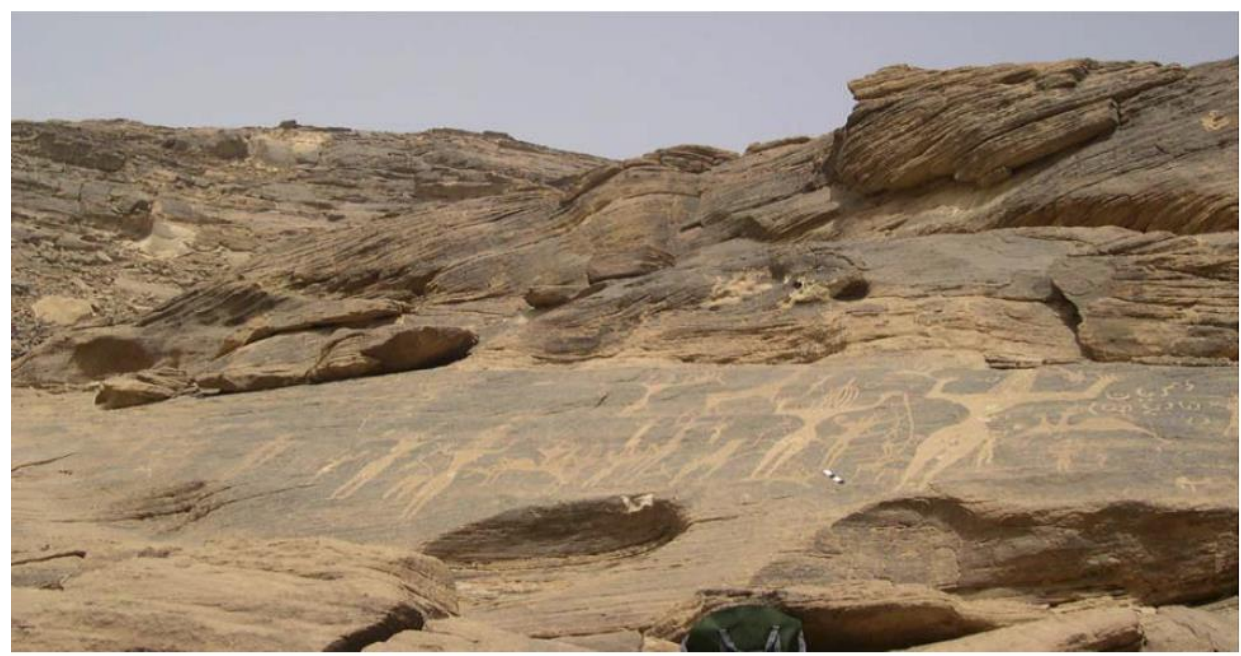


The art inherent in the inscriptions and figures on the rocks, cliffs and caves of Saudi Arabia, the beauty, skill of craftsmanship, and mystery of images, captivate the visitor in a magical way, who is moved and fascinated by the petroglyphs found all over the Arabian Peninsula (Figures 17 and 18).

Figure 17. The most fascinating rock art site at Jabal Umm Sanman, Jubbah, Northern Arabia.

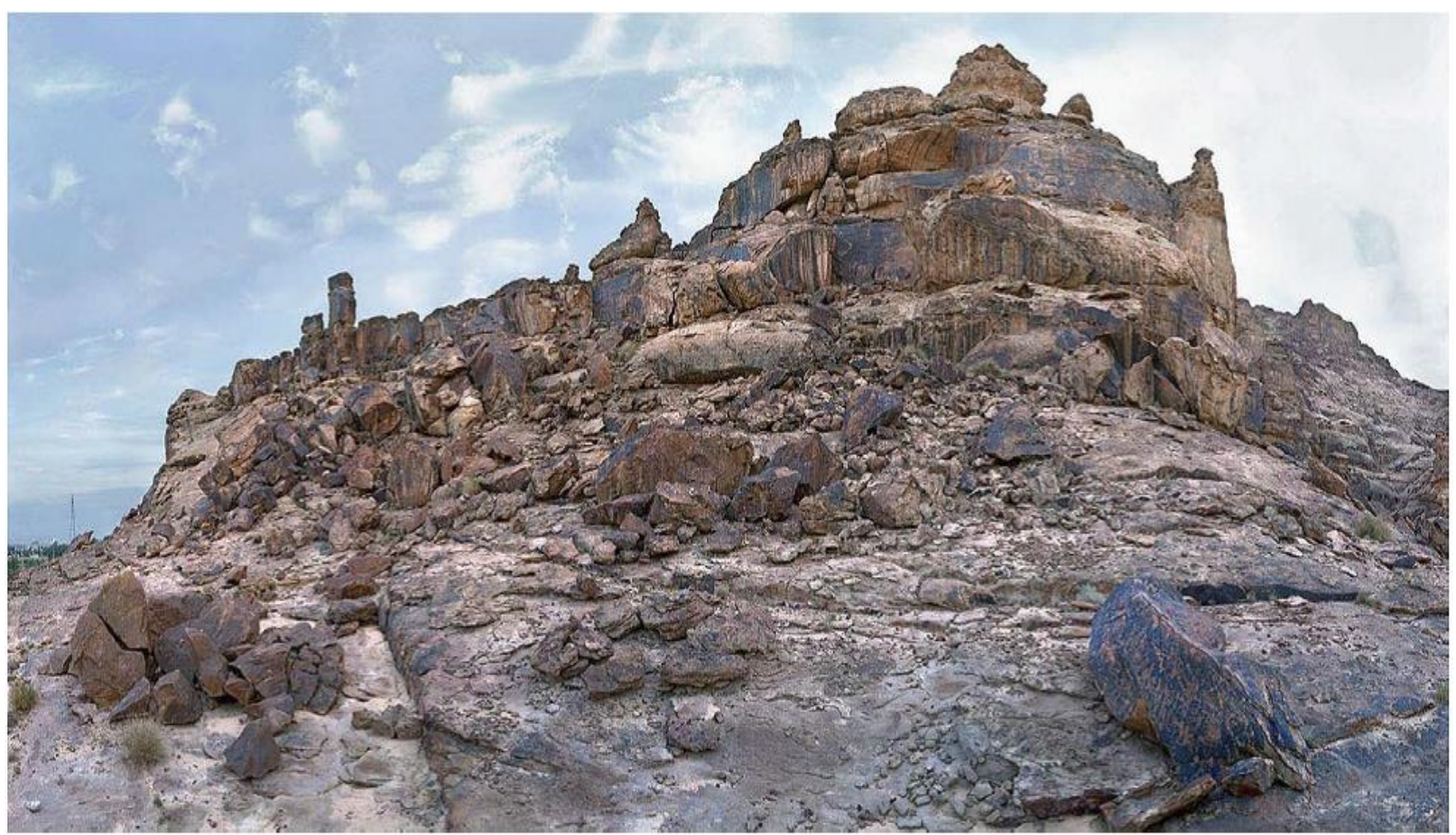

Figure 18. The prehistoric artist choose this smooth vertical surface of a large boulder to create one of the most fascinating and outstanding work of art. When the sun rays fell at dawn on this east-facing rock art panel, the figures become shining and reflective, and in a moon-lit night, the entire rock shines like a bowl of light creating a strange, calm, and soothing atmosphere. On a calm, moonlit night, when one stands in front of the rock, one can feel as if someone is playing the rubab. The female figure, with prominent sexual traits, radiating hair, the crescent-shaped motif near the head, and apparently various phases of moon marked on her body, is in a standing posture with half-raised arms, while a man looking at the girl who is playing the rubab (a traditional Arab musical instrument still used by the Bedouins). The panel is unique, located in a very remote, rugged, isolated, and hardly accessible area in Najran, southern region. There is a considerable time difference between the superimposed inscriptions and the human figures, which are older than the later writings. 


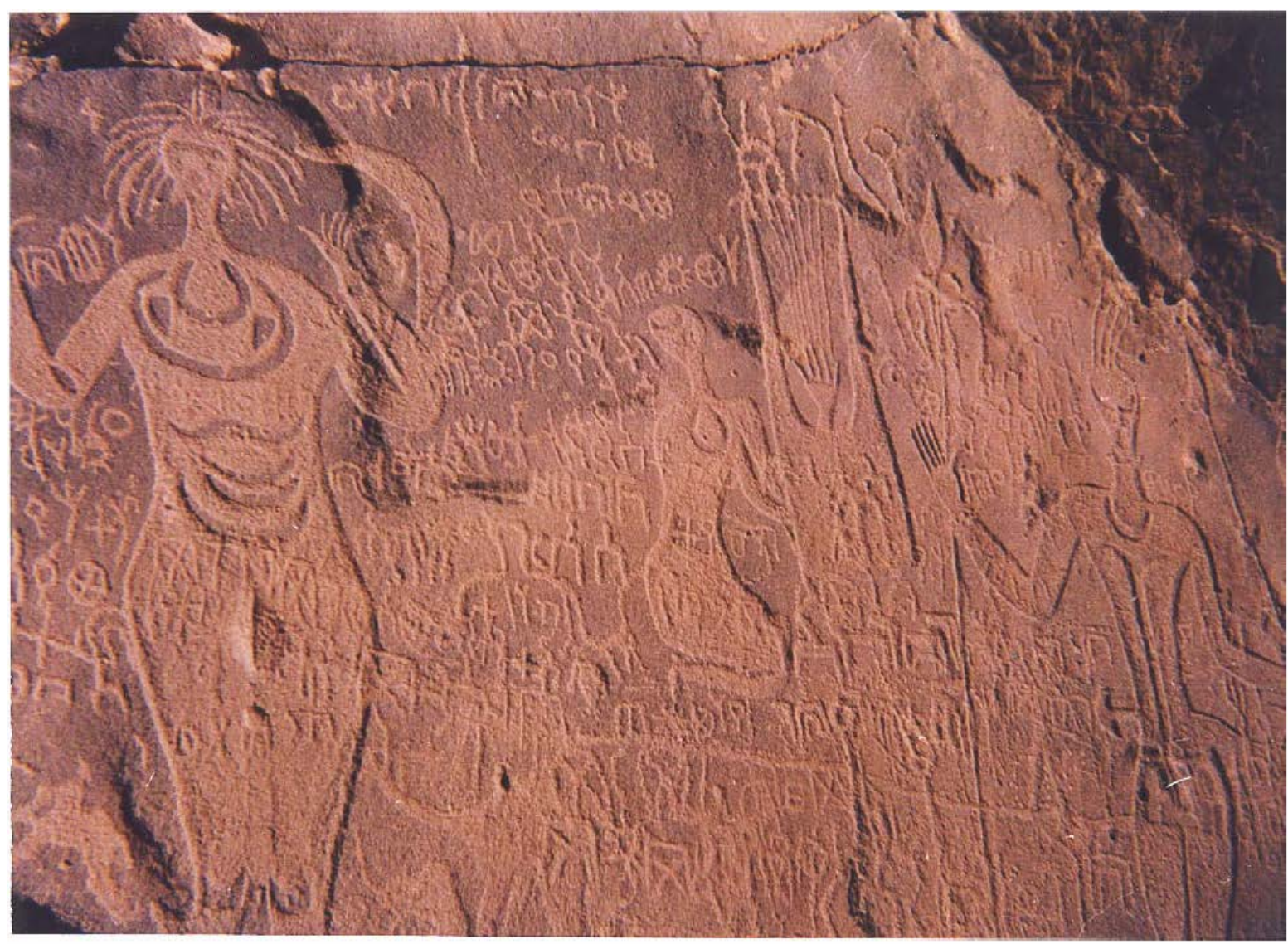

\section{Diversity in Saudi Arabian Rock Art}

For a long time archaeologists had the idea that pastoralists and nomadic Bedouins living in a harsh desert environment would leave little or no records of their culture. However, recent archaeological and rock art surveys and investigations carried out by the Saudi Department of Antiquities and Museums have not only dismissed all such previous assumptions, on the contrary they revealed a tremendous amount of cultural material in the deserts of Saudi Arabia.

It is very interesting that the rock art of Saudi Arabia represents the same animals with which the local population was aware and which were found in this part of the world, such as cattle, camels, deer, gazelles, dogs, snakes, lizards, goats, etc. Surprisingly no flora (with the exception of a couple of sites with presumed date trees) and no birds except ostriches were depicted. Thus, the artists chose some animals from their environment and depicted them on the rocks and overlooked other animals which were as relevant for them and were part of their ecology and environment. This is a universal phenomenon and everywhere in Europe, Africa, Australia, or Asia, the same tendency has been observed. It means that artists in various parts of the world had the same intellectual, ideological, and mental approach $[9,3]$. 
Figure 19. This unique and meaningful composition of human and animal figures is located north of Himma, Najran, Southern Arabia. It is carved on a hardly accessible, steep and vertical surface of a 200-m-high hill. The figures are facing east and are visible from a long distance. There is absolutely no place to stand on the steep hill surface to carve the figures. It was even difficult to photograph the panel. Perhaps the artist might have descended from the top of the hill, hanging on a rope to carve the figures. The man is tall and muscular while the woman is short and stout. Man, woman, and the "ibex" are placed closely to show complete synchronization and unity. The panel gives the impression as if the artist wanted to represent love, sex, and man's power and superiority over the woman. He seems to be holding a shield and a lance in the left arm and a spear in the right arm, touching the horns of the "ibex". The female is depicted under the armpit of the man, slightly bending as if seeking protection under the arm of the man. The artist has emphasized the sexual traits. The camel figures on the same rock are later additions.

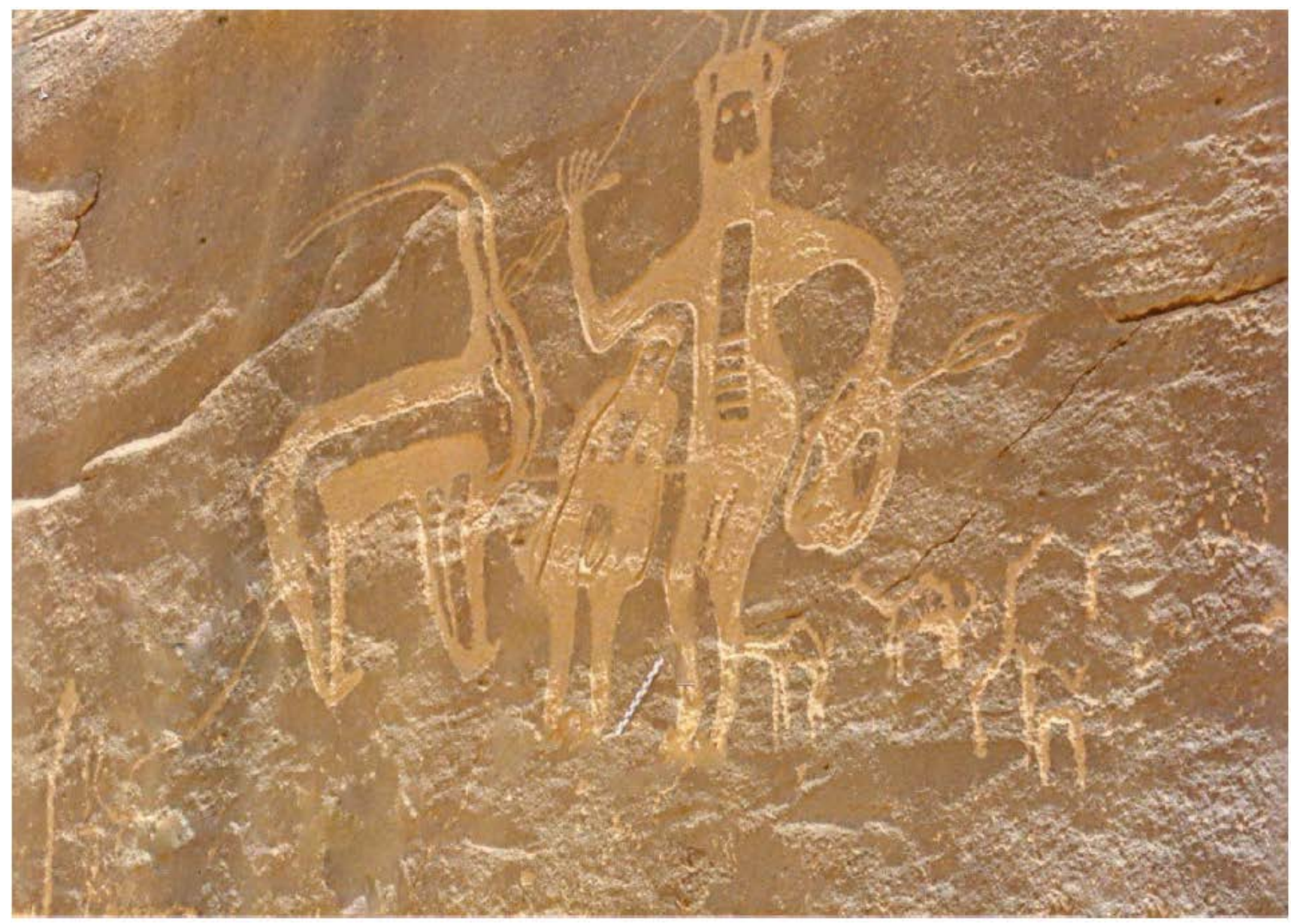


Figure 20. An elegant human figure at Jubbah, Northern Saudi Arabia. Local people called it the image of a king who is shown in sitting posture with his "attendant" standing in front of him.

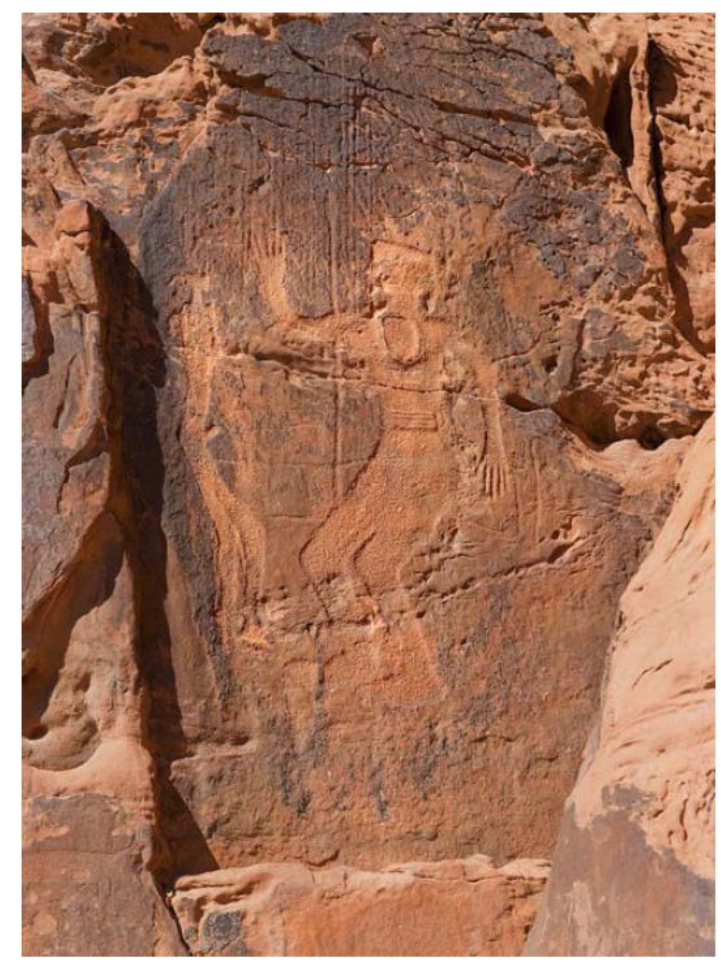

The chronology of Saudi Arabian archaeology indicates a continuity of human presence in the Arabian Peninsula from Acheulian to the present day [1]. However, the rock art of Saudi Arabia represents an era from early Neolithic, beginning ca. 9500 BP [2002] [11] to the early Islamic period (ca. $650 \mathrm{AD}$ ). The chronology of rock art from Neolithic (Figures 21 to 23) until the early Islamic period is proof that the aesthetic urge and the intention to preserve cultural heritage is not a recent refinement of human civilization, but part of an ancient, deeply rooted activity of the ancestors.

Figure 21. Neolithic stone objects from Jubbah, from the period to which some of the petroglyphs there are attributed.
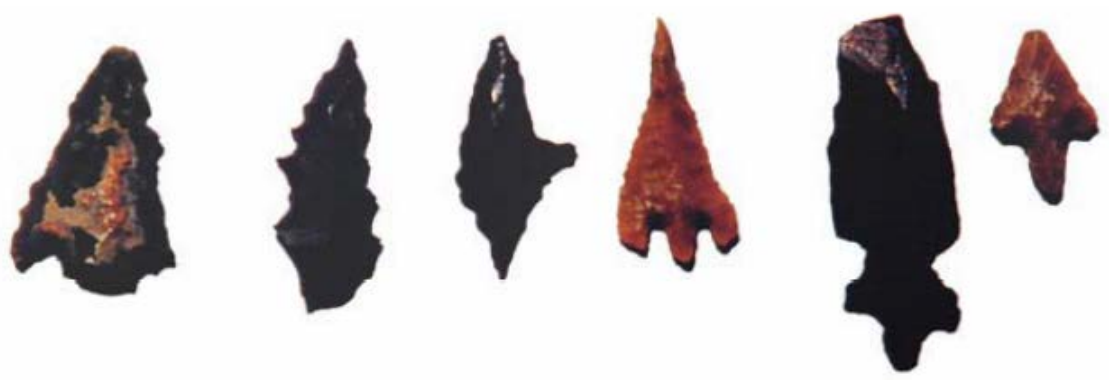
Arts 2013, 2

Figure 22. Stone objects from Shuwaymis.

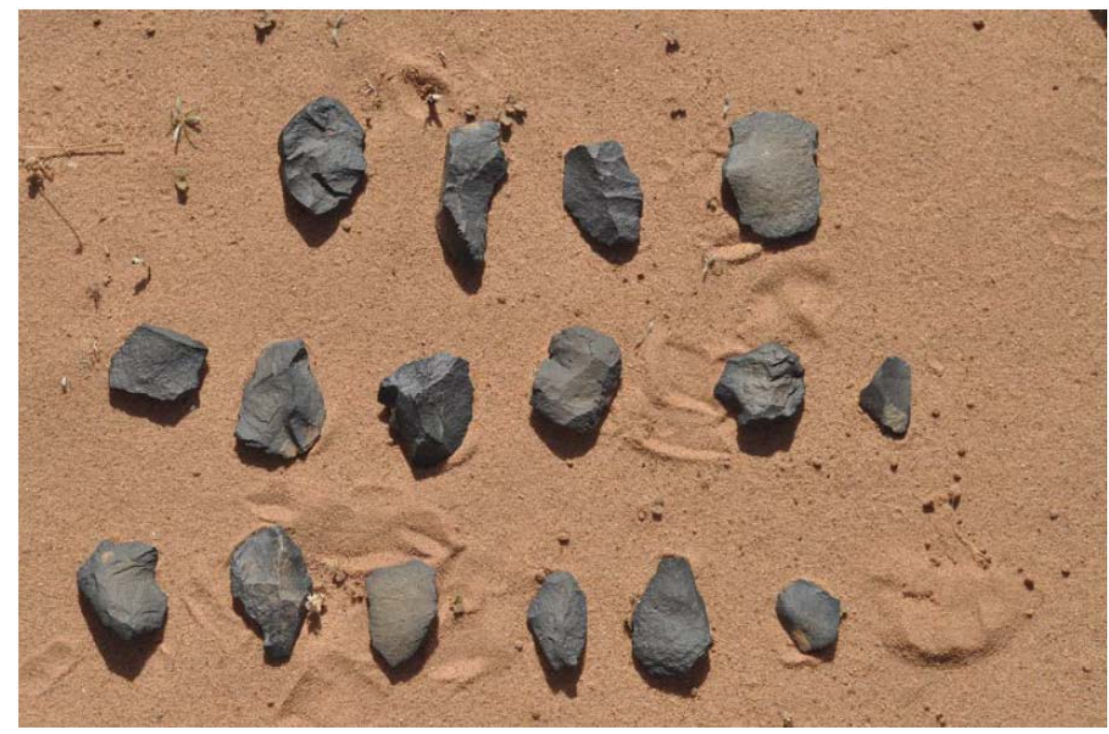

Figure 23. Standing in front of this rock art panel near Jubbah, Northern Arabia, one gets the impression as if they are Adam and Eve (author's personal impression). The petroglyphs are probably from the Neolithic.

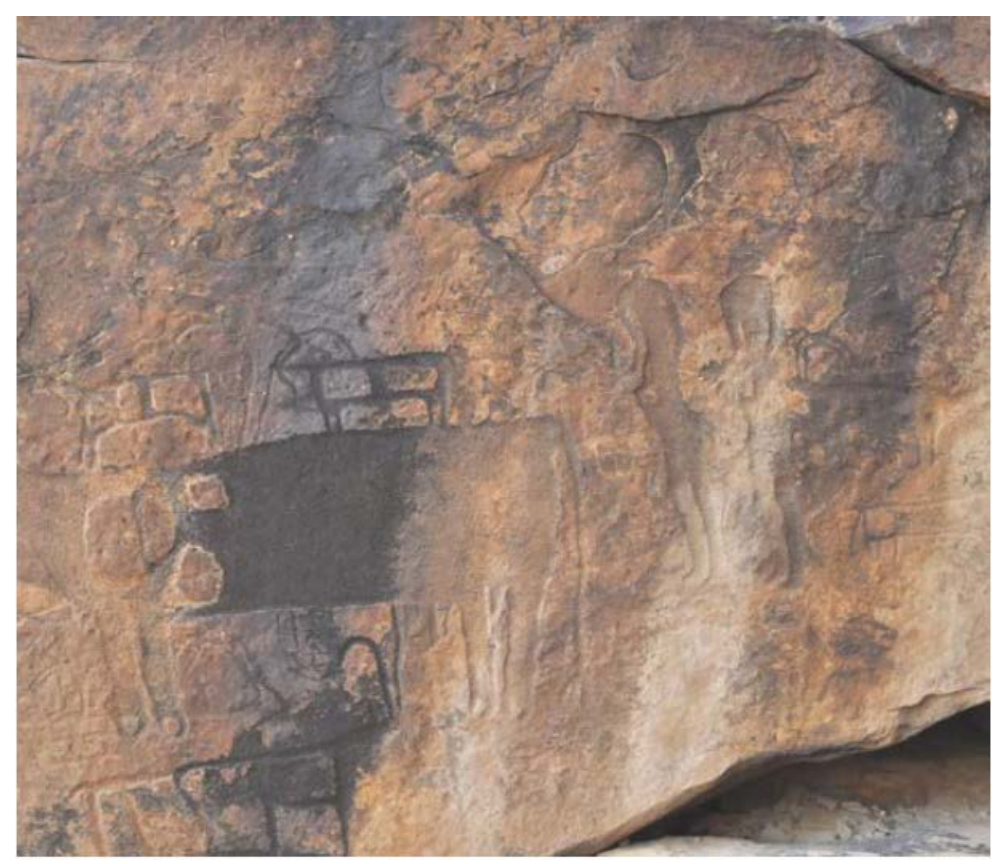

The oldest and earliest petroglyphs of human footprints in Saudi Arabia are probably those located at the site Jabal al-Raat, of the Shuwaymis rock art complex, northern region. Recently, a cupule, a hemispherical small circular petroglyph of the same panel was scientifically dated by Bednarik and Khan (2013 under publication) to 9330-6220 years BP. The foot prints are deeply 
pecked on the sloping flat surface of a hard sandstone rock. These almost natural-size foot prints of an adult and a child, pecked deeply in the rock, have survived for thousands of years (Figure 24).

Figure 24. Some of the human footprints at Jabal al-Raat, Shuwaymis.

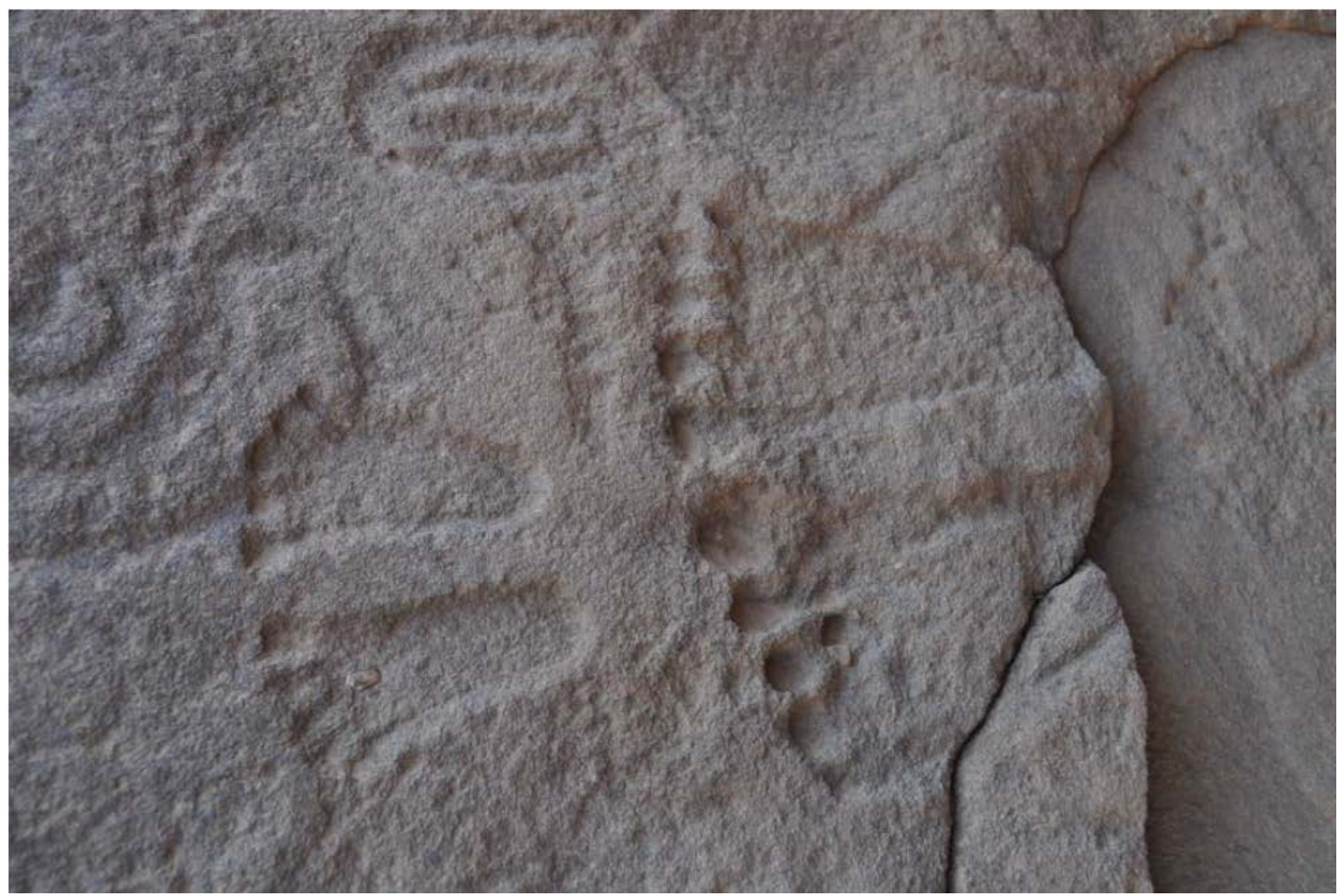

Hand motifs also occur in Arabian rock art, not only as petroglyphs, but, occasionally, also as rock paintings. They often give the impression of having conveyed some specific meaning to the contemporaries of the rock artist (Figure 25). There are even cases when the actual meaning is accessible (Figure 26). As in much of the rest of the world, hand stencils were made by placing hands on flat rock surfaces and spraying pigment around them (Figure 27). 
Figure 25. The camel has always been the most valuable desert animal. Its images are found in almost all parts of the country, often associated with Bedouin inscriptions and/or tribal symbols (such as the cross), as in this composition, indicating the name of the camel's owner.

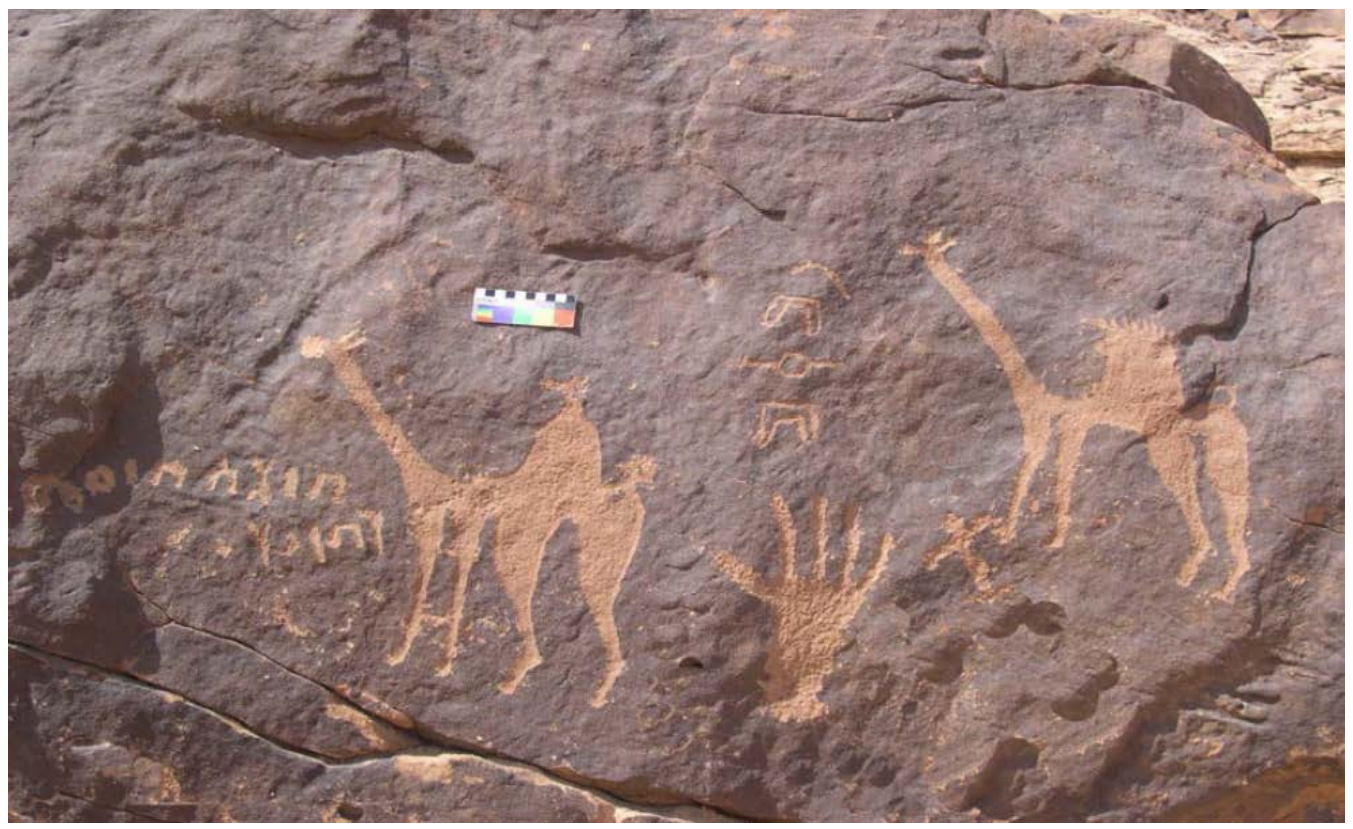

Figure 26. Hand associated with Arabic inscription that says "this is the hand of Sulaiman al-Yemeni”.

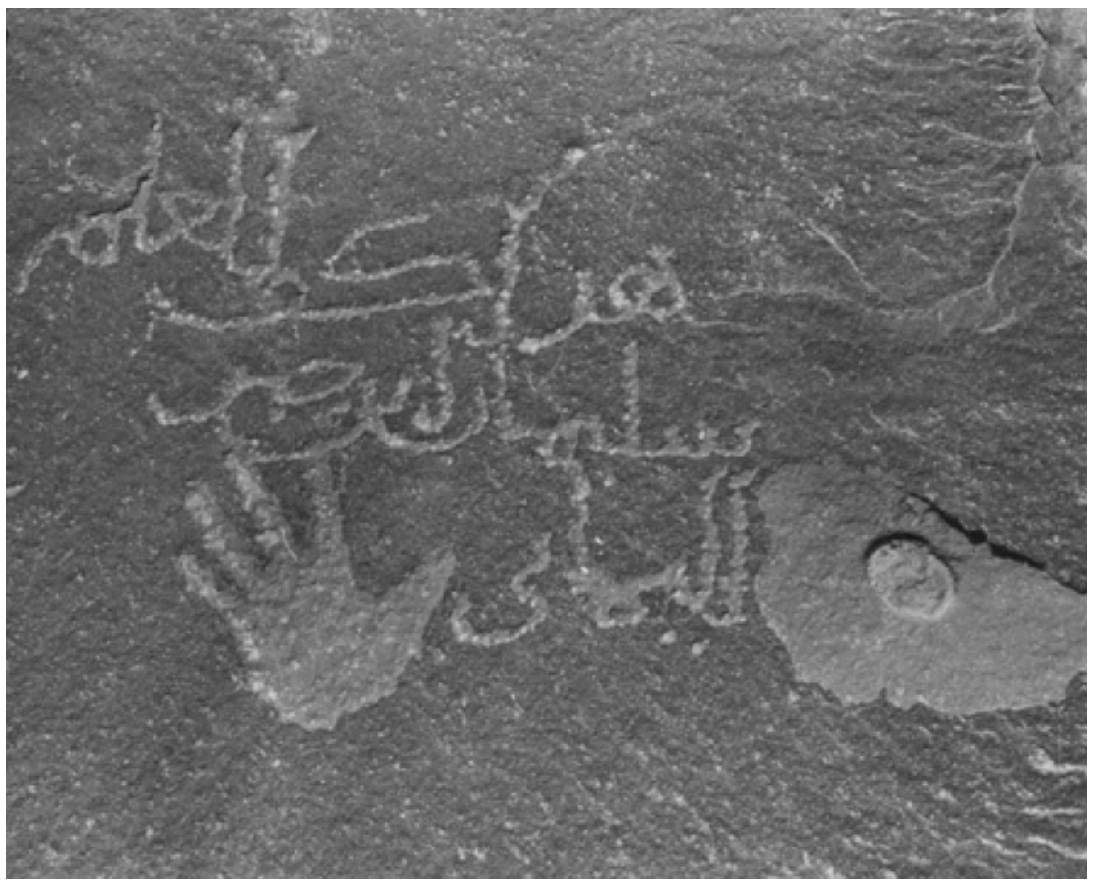


Arts 2013, 2

Figure 27. Hand stencils from Wadi Qara, Jazan area.

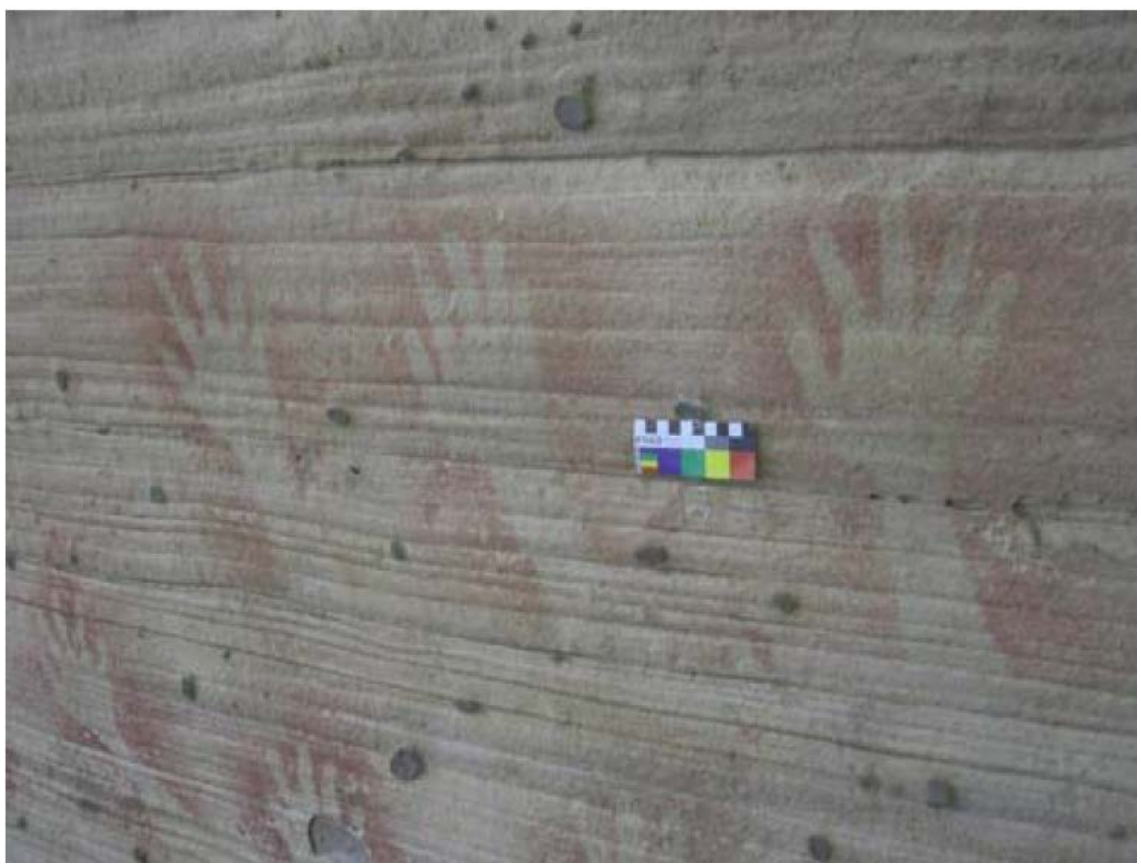

Other compositions were evidently very meaningful to the initiated viewer, but their significance is entirely unknown nowadays. An example are the stretched arms with open fingers and a wheel-like figure in association with a fading human figure and other unidentified images, all together seemingly forming a single composition of a message for those who lived at that time and who could understand it, but we have no means to do so (Figure 28).

Figure 28. A series of human arms with hands and several other elements presenting an enigmatic message.

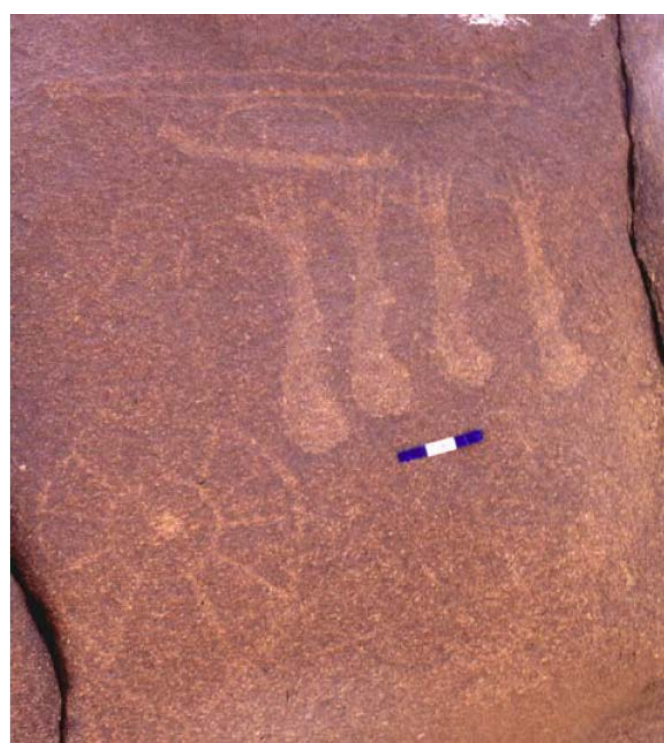


While the modern viewer is often tempted to believe that the original meaning of the rock art can be known, a very large component of Saudi Arabian rock art, thus, seems to be well beyond rational explanation, and it then tends to be seen as “abstract”, “mystical”, or “magical”, or as part of some religious symbolism. Two examples of such presumed compositions are given (Figures 29 and 30).

Figure 29. The components of this apparent composition seem to have been made at different times, in which case, it is either a cumulative group either of unrelated motifs, or of successive graphic responses to pre-existing motifs.

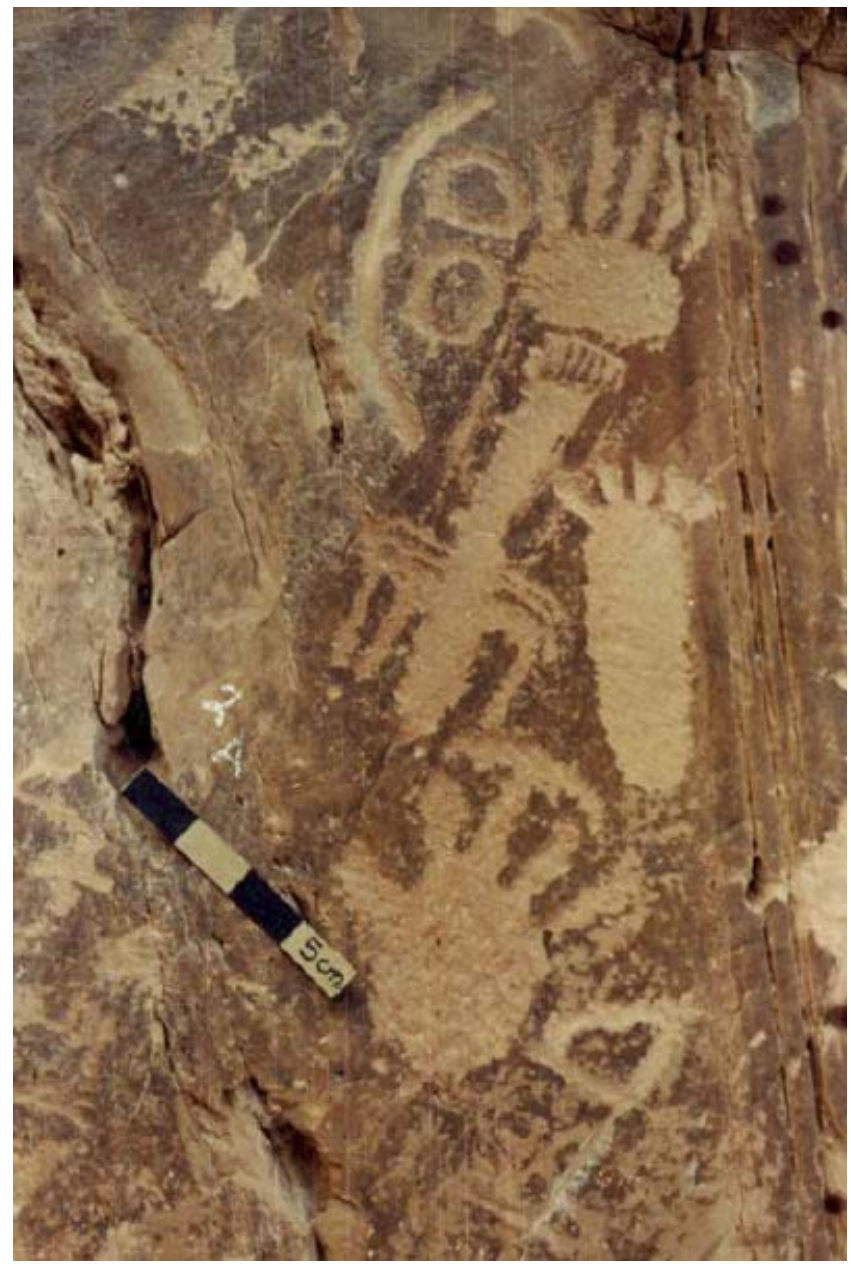


Figure 30. This example of symbolic arrangements, including hand and foot motifs and series of cupules (cup marks), is located near Sakkaka, northern region of Saudi Arabia.

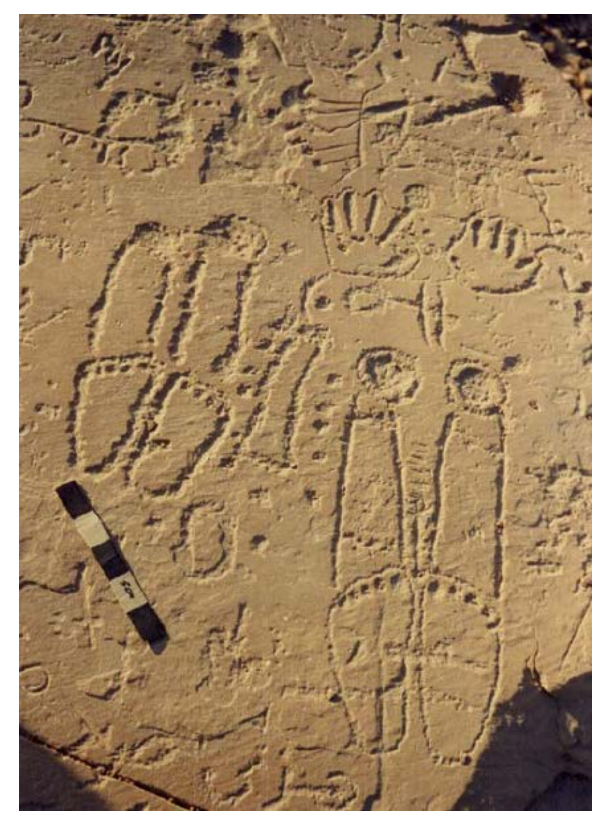

Female figures with triangular torsos, long necks, narrow waists, wide buttocks, and long hair are representative of Arab ideals of female beauty, which remain the same today in our modern societies. As noted above, Southern Arabia was the center of such female deities or goddesses, which we do not find in the north, where figures of women are extremely rare (Figure 31).

Figure 31. Several petroglyphs purportedly depicting the deity and queen Alia, Najran region.

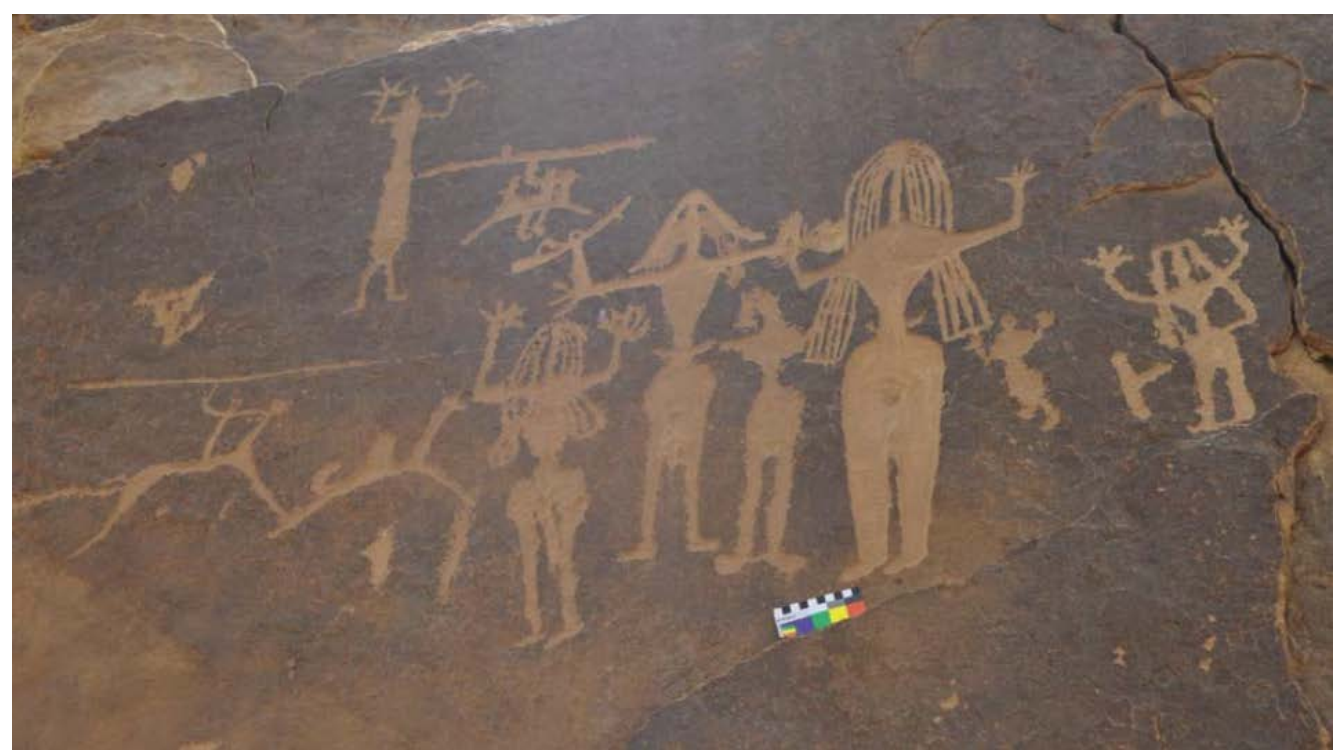


The horse was domesticated and bred for marketing on a large scale in the early Islamic period, when it provided the major transport of Islamic armies. However, the horse was present in Arabia from times unknown. In the north of the Kingdom of Saudi Arabia, the horse figures are sometimes associated with Thamudic inscriptions, mentioning the names of their masters (Figure 32). Some petroglyphs seem to convey the long-standing and enduring ideals of equine beauty (Figure 33). Chariots also occur in Arabian rock art, but are not as common as in other parts of Asia and Northern Africa (Figure 34).

Figure 32. Horse petroglyphs occurring together with the Thamudic names of people, presumably their respective owners.

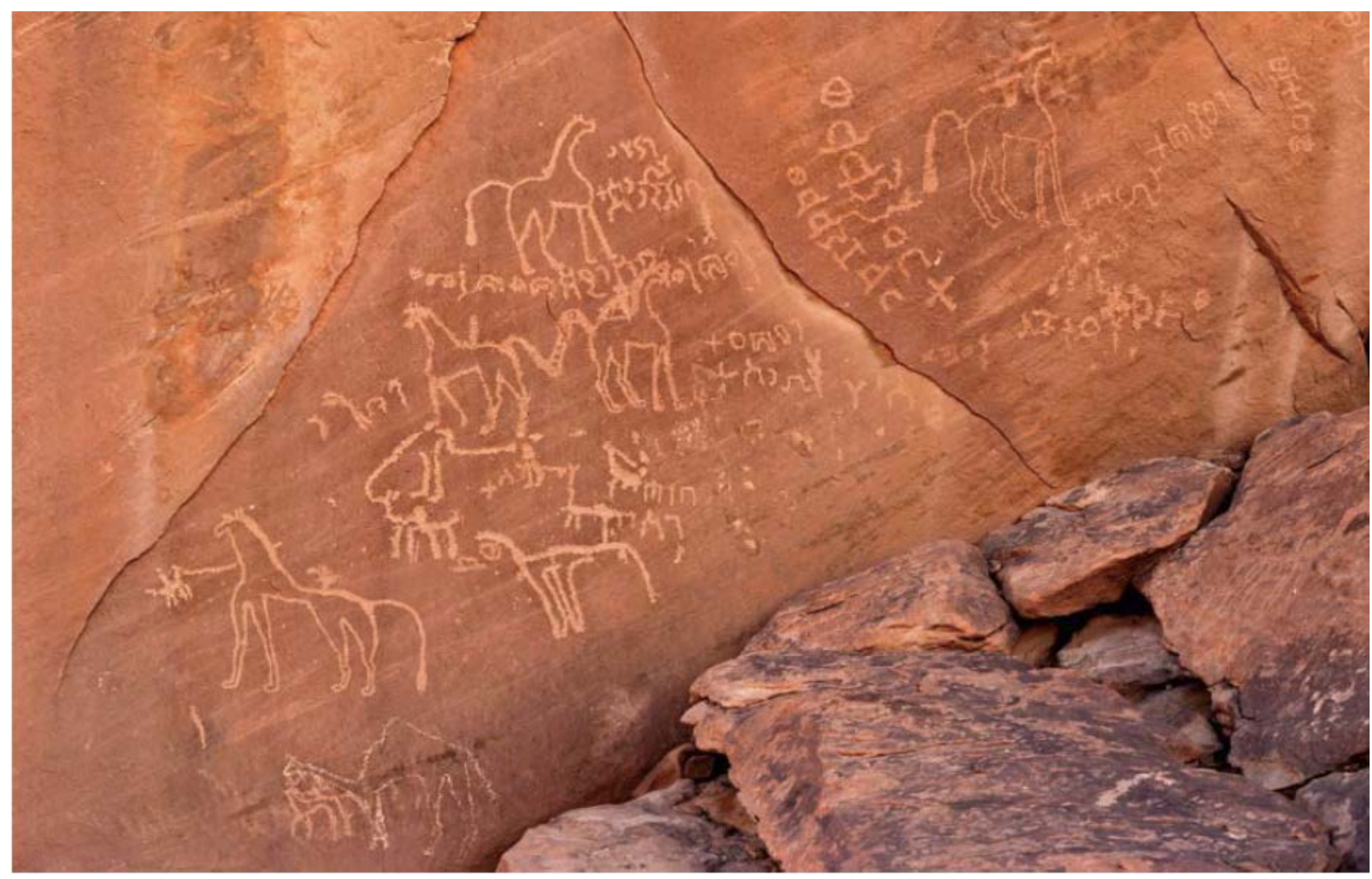


Figure 33. The stallion is exactly the same today as it was 3000 years before, as shown in this petroglyphs of a horse, located near Tayma, northwest of Saudi Arabia.

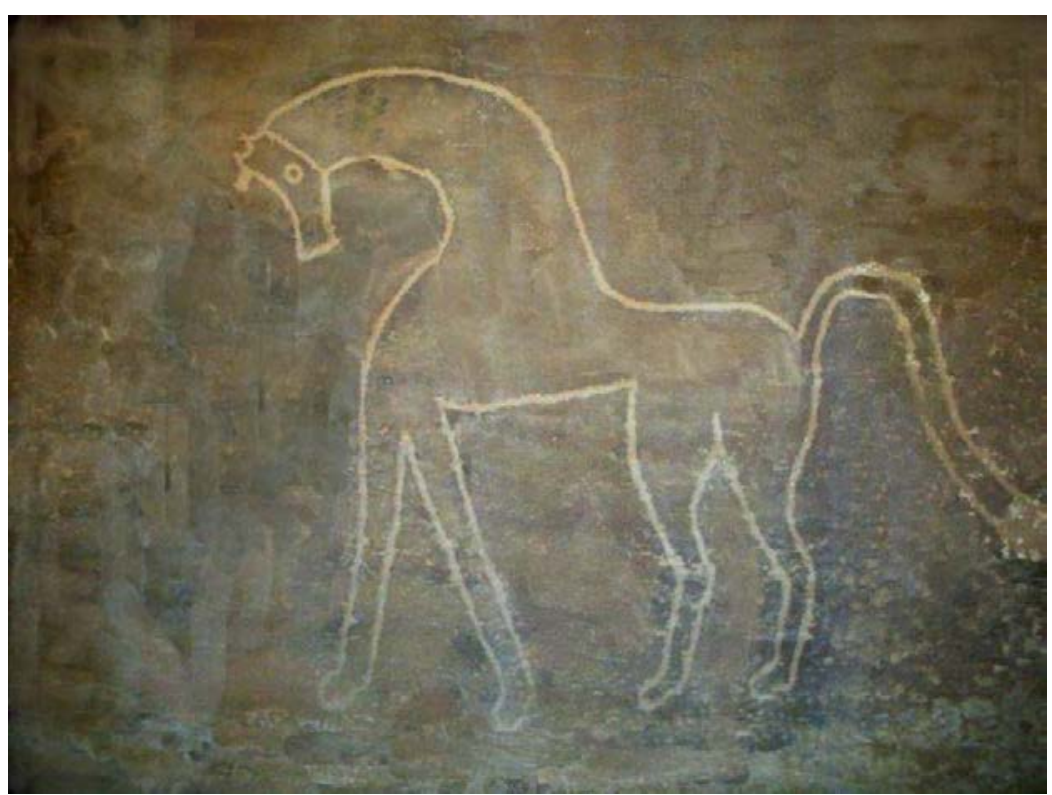

Figure 34. Chariot in Arabia associated with Thamudic inscription, perhaps indicating the names of the passengers. Located near Tayma, NW of the country.

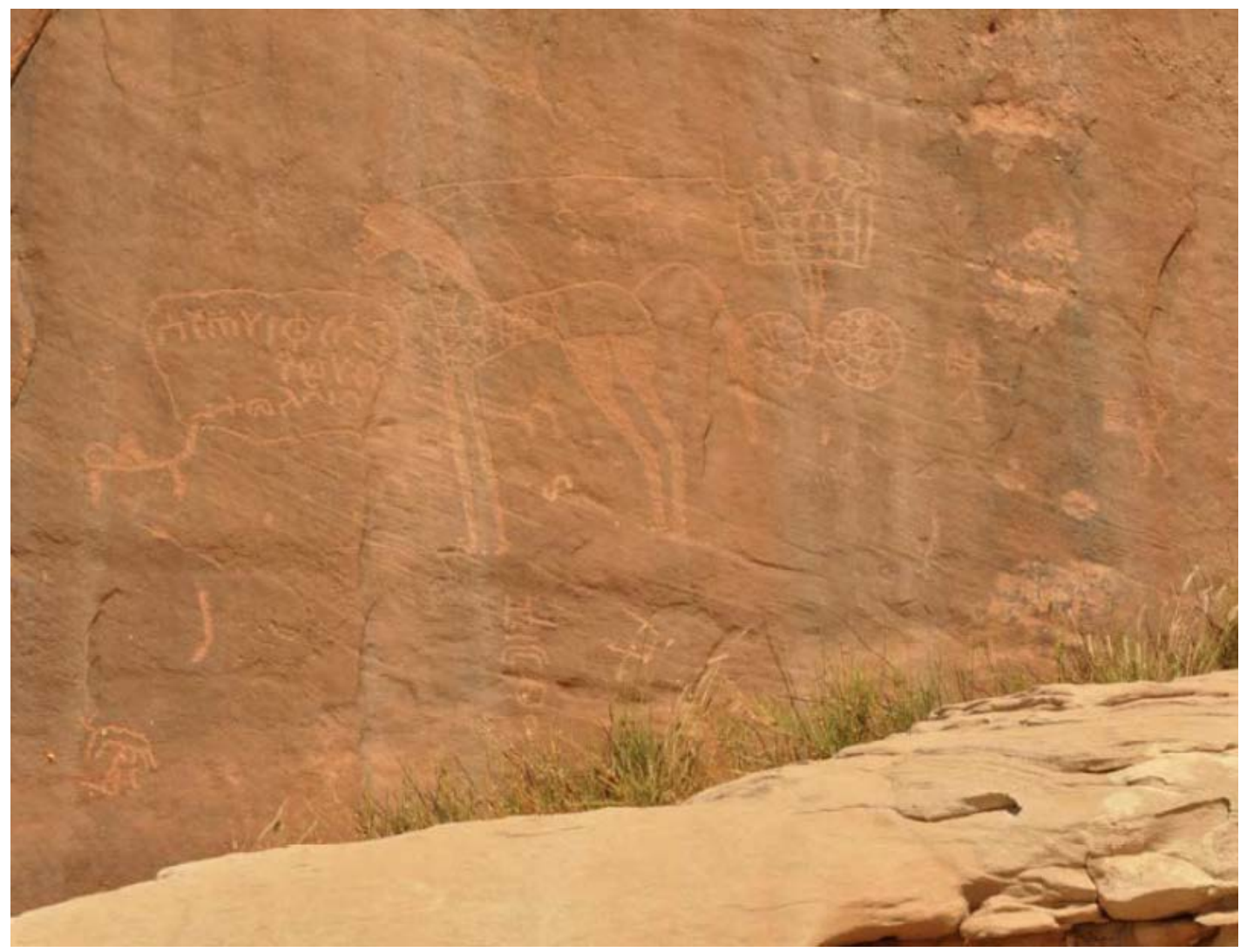


A strange, but beautiful, product of nature is a large rock that is split in two parts as if cut by a jigsaw, located in the same region, mid-desert near Tayma, in the northwest of the country (Figure 35). Petroglyphs of horses, camel, and humans were created at various times and in different cultural periods.

Figure 35. The incredible split rock near Tayma.

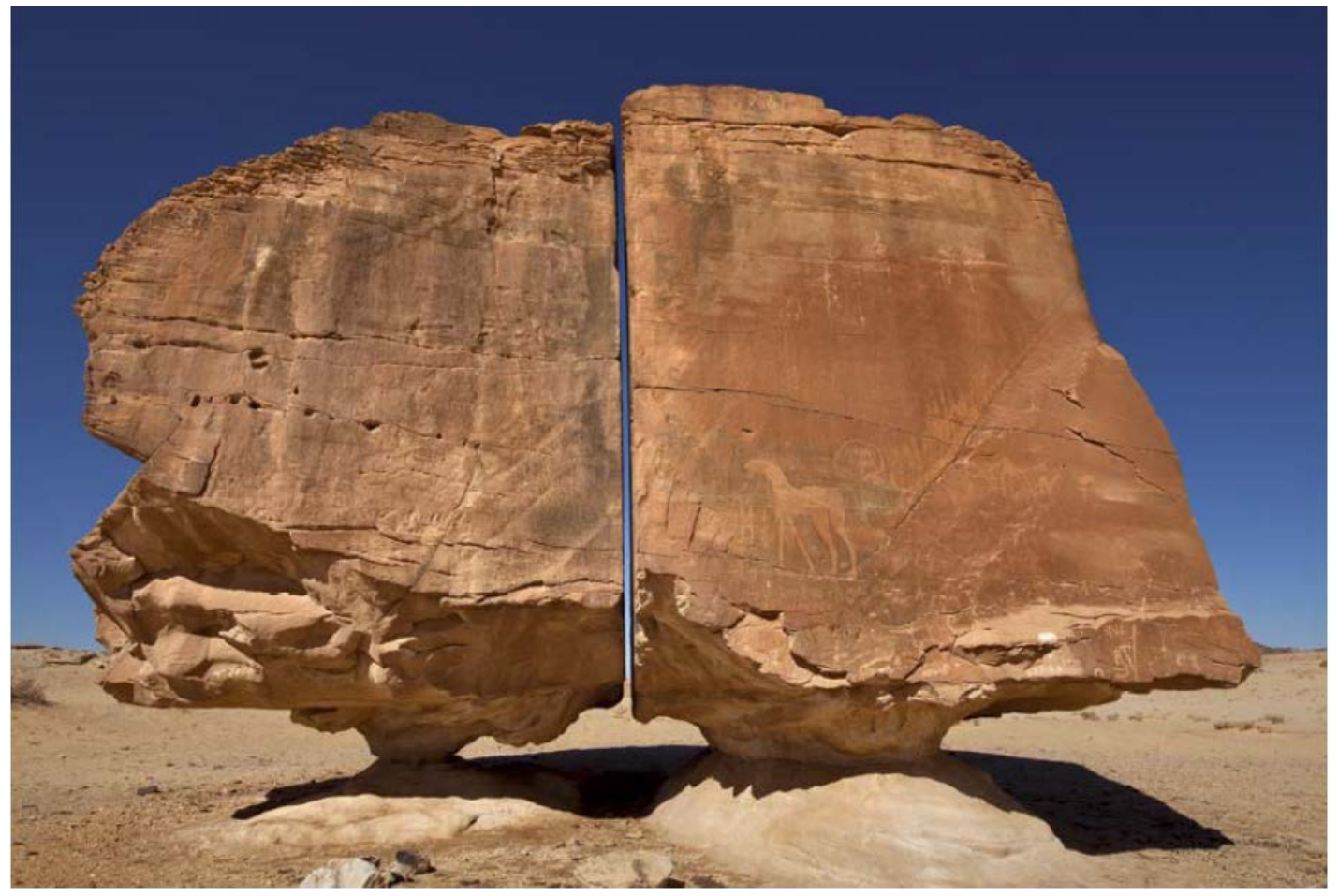

\section{Conclusion}

The desert life is usually hard and difficult. Living in extreme hot and dry conditions, with very little to live on, and in harsh and inhospitable environment, may not be attractive for us, but for those Bedouins, the real indigenous Arabs, the desert is their heaven. Their love for that land can be seen to this day when, in spite of all modern facilities in the towns and cities, and with all attractive offers from the Government still, some Bedouins refuse to leave their land and their culture. Hundreds and thousands of petroglyphs and ancient Arabian inscriptions, located throughout Saudi Arabia, suggest that the population of Arab Bedouins in prehistoric times was reasonably large, but, at the same time, sparse and unevenly distributed.

The origin of rock art in Saudi Arabia is still not clear. The oldest sites at Shuwaymis, Kilwa, and Jubbah located in the northern areas of the country show well-developed and skilled work of artistic activities. There is no evidence of local evolution, nor are there parallels to the so-called "naturalistic" human figures located at Shuwaymis or Jubbah, or in the neighboring regions such as Jordan, Sinai, Negev, and Palestine. Although, styles and techniques suggest a long tradition 
of specialized activity, it must be assumed, in the absence of evidence to the contrary, that North Arabian art developed independently. Davis [19] and Ucko [20] have both suggested that the very earliest art forms could just as likely to have been representational as non-representational contra Marshack [21] and Breuil [22], it would be in keeping with this argument that there would not necessarily have been any predecessors of North Arabian rock art, nor any parallels to the (advanced) Shuwaymis or Jubbah rock art. Such early art work does not appear to have developed elsewhere in the Arabian Peninsula or its neighboring countries (Jordan, Palestine, Negev or Sinai, Egypt, etc.) Therefore, we may suggest that this unique and highly stylized and sometime schematized art was possibly created and developed at Shuwaymis and Jubbah without being subject to external influence. Alternatively, techniques learned elsewhere may have been adapted to local styles. Despite the apparent discontinuity in art style, contents, and subjects at Shuwaymis, its abrupt end; and appearance of new art style and subject matter in the subsequent Chalcolithic period, there is no evidence of discontinuity of human activity, for lithic material of almost all periods has been found [1] in other parts of Northern Saudi Arabia. The discontinuity of art at Shuwaymis and Jubbah becomes all the more striking when compared to subsequent developments in other parts of Arabia, as an iconographic sequence can be traced without obvious interruption from the Neolithic to the pre-Islamic periods [23,24,4] Hundreds and thousands of rock art galleries that contain canvasses of prehistoric artists are the manifestation of our ancestor's social, cultural, and religious life.

\section{Acknowledgments}

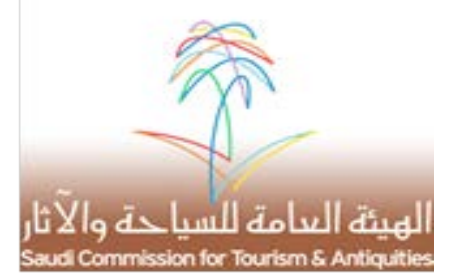

I am extremely thankful to Ali I. Ghabban, Vice President of Saudi Commission for Tourism and Antiquities under whose supervision the SCTA organized and facilitated all field activities, survey and investigations.

\section{Conflicts of Interest}

The author declares no conflict of interest. 
Arts 2013, 2

\section{References}

1. Whalen, N.M.; Siraj-Ali, J.S.; Sindi, H.; Pease, D.W. A lower Pleistocene site near Shuwayhitiyah in northern Saudi Arabia. Atlal 1986, 10, 94-101.

2. Khan, M. Recent Rock Art and Epigraphic Investigations in Saudi Arabia. In Proceedings of the Seminar for Arabian Studies, Oxford, UK, 24-26 July 1990; University of London: London, UK, 1991.

3. Khan, M. Prehistoric Rock Art of Northern Saudi Arabia. Ph. D Thesis, University of Southampton, Southampton, UK, 1993; Ministry of Education: Riyadh, Saudi Arabia.

4. Khan, M. Rock Art of Saudi across Twelve Thousand Years; Ministry of Education: Riyadh, Saudi Arabia, 2007.

5. Khan, M.; Kabawi, A.; Al-Zhrani, A. Preliminary report on the second phase of rock art and epigraphic survey of northern Saudi Arabia. Atlal 1986, 10, 465.

6. Khan, M. Jubbah - The Land of Golden Sand and the Lost Civilization of Arabia; Saudi Commission for Tourism and Antiquities: Riyadh, Saudi Arabia, 2010.

7. Garrard, A.; Harvey, C.P.D. Environment and settlement during the upper Pleistocene and Holocene at jubbah in the Great Nafud, North Arabia. Atlal: J. Saudi Arab. Archaeology. 1977, 5, 137-156.

8. McClure, H.A. Radiocarbon chronology of late Quaternary lakes in the Arabian desert. Nature 1976, 263, 755-756.

9. Khan, M. Origin and Evolution of Ancient Arabian Inscriptions; Ministry of Education: Riyadh, Saudi Arabia, 1993.

10. Bednarik, R.G.; Khan, M. The Saudi Arabian rock art mission of November 2001. Atlal 2002, 17, 75-99.

11. Bednarik, R.G. Scientific study of Saudi Arabian rock art. Rock Art Res. 2005, 22, 49-81.

12. Khan, M. Human Figures in the Rock Art of Saudi Arabia; International Rock Art Congress: Ripen, WI, USA. 1999, 48.

13. Clarke, C. Rock Art at Jubbah, Northern Saudi Arabia. Proceedings of the Seminar for Arabian Studies. Institute of Archaeology London, 1979, vol.4, 80-81

14. Khan, M. Wusum - the tribal symbols of Saudi Arabia. Bilingual (Eng./Arabic) published by the Ministry of Education, Kingdom of Saudi Arabia, 2000.

15. Khan, M. Bir Himma - the Center of Prehistoric art and culture. Admatu 2000, 6.

16. Khan, M. Rock art and epigraphic survey of northern Saudi Arabia. Atlal 1988, 11, 61-75.

17. Abu-Duruk, H.I. A Critical and Comparative Discussion of Certain Ancient Monuments in the North Arabian City of Tayma in the Light of Evidence Furnished by Excavations. Ph. D Thesis, Ministry of Education, Riyadh, Kingdom of Saudi Arabia, 1986. 
18. Khan, M. Sacred Images of Metaphysical World- Perspective of Prehistoric Religion in Arabia. XXII Valcamonica Symposium 2007. Rock Art in the frame of the Cultural Heritage of Humankind papers.

19. Davis. W. The origin of image making. Current. Anthropology. 1986, 27, 193-215.

20. Ucko, P.I. Debuts illusoiresdansl'etude de la tradition artistique. Bulletin de la Societe Prehistorique Ariege-Pyrenees 1987, 17, 38-50.

21. Marshack, A. Roots of Civilization: Cognitive Beginning of Man'S First Symbol and Notation; Weidenfeld and Nicholson: New York, NY, USA, 1972.

22. Breuil, H. Four Hundred Year of Cave Art; Hacker Books: New York, NY, USA, 1952.

23. Khan, M. Rock art and epigraphic survey of northwestern Saudi Arabia. Atlal 1985, 9, 1428.

24. Khan, M. Rock Art Research in the Arabian Peninsula, Levant and Anatolia. News of the World 1996, 95-103. Edited by Paul Bahn and Angelo Fassati. Oxbow Publications.

2013 by the author; licensee MDPI, Basel, Switzerland. This article is an open access article distributed under the terms and conditions of the Creative Commons Attribution license (http://creativecommons.org/licenses/by/3.0/). 